\author{
Juan Sevilla Álvarez \\ Departamento de Geografía. Universidad de Oviedo
}

\title{
El paisaje de la producción láctea en Asturias. Especialización ganadera y organización cooperativa en Carcedo y Muñás (Valdés), entre 1960 y $1985^{1}$
}

\section{RESUMEN}

En este artículo se estudia la evolución de espacios ganaderos asturianos que, influidos por el desarrollo de la transformación alimentaria en fábricas, se especializan en la producción de leche entre la posguerra y la entrada en la CEE. Se atiende al ejemplo de las parroquias de Carcedo y Muñás (valles afluentes del Esva, occidente de Asturias) por haber desarrollado una iniciativa pionera de cooperativismo agrario en el contexto agroalimenario señalado.

\section{RÉSUMÉ}

Le paysage de la production du lait dans les Asturies. La spécialisation en élevage et l'organisation coopérative à Carcedo et Muñás (Valdés) entre 1960 et 1985.- Cet article traite de l'évolution de l'élevage dans des secteurs asturiens qui ont été influencés par le développement de l'industrie alimentaire et sont devenus des espaces spécialisées en production du lait au cours de la seconde moitié du $\mathrm{Xx}^{\text {ème }}$ siècle (avant l'adhésion d'Espagne à la $\mathrm{CEE}$ ). Une attention spéciale est prêtée à l'exemple des paroisses de Carcedo et Muñás (vallées affluentes de l'Esva, ouest des Asturies) pour avoir mis au point une initiative pionnière de coopérative agricole dans le contexte agroalimentaire indiqué.

\section{INTRODUCCIÓN}

$L$ a capacidad de la industria agroalimentaria y, específicamente, de la industria láctea para promover la

\footnotetext{
${ }^{1}$ Esta investigación se ha elaborado en el marco del proyecto de investigación estatal "Diseño de un sistema de localización de fotografías aéreas históricas (España). Aplicaciones a la docencia, la investigación, el planeamiento y la ordenación del territorio" (clave de referencia: CSO2012-32428) y del contrato de investigación Geografía de España (Art.83 FUO Universidad de Oviedo).
}

\begin{abstract}
The landscape of milk production in Asturias. Livestock specialization and cooperative organization in Carcedo and Muñás (Valdés) between 1960 and 1985.- This article aims to study the evolution of livestock Asturian spaces being influenced by the development of food industry and specializing in milk production during the second half of the $20^{\text {th }}$ century (before Spain's entry into the EEC). A special focus is on the example of the parishes of Carcedo and Muñás (Esva tributary valleys, western Asturias) for having developed a pioneering initiative of agricultural cooperative.
\end{abstract}

\section{Palabras Clave/Mots Clé/Keywords}

Producción láctea, ganadería, paisaje, cooperativa, Carcedo, Muñás (Asturias).

Production du lait, élevage, paysage, coopérative, Carcedo, Muñás (Asturies).

Milk production, cattle raising, landscape, cooperative, Carcedo, Muñás (Asturias).

transformación del medio rural que le suministra materias primas tiene un interés geográfico notable. En el contexto de la industrialización contemporánea, paulatinamente acompañada del crecimiento del sector terciario, el aumento de la demanda de alimentos en cantidad, calidad y diversidad, favorecido por la difusión de estudios científicos sobre nutrición y salud, así como por la política de las administraciones y el aumento de los niveles de renta y del poder adquisitivo, ha estimulado el desarrollo de 
la rama industrial dedicada a la producción de alimentos (Langreo Navarro, 1995; Segrelles Serrano, 1999; Espejo Marín, 2001; Collantes Gutiérrez, 2014). También incide en este fenómeno la progresiva concentración geográfica del consumo debida a las repercusiones demográficas del proceso de industrialización. El empleo de máquinas en sistemas de producción, conservación y envasado progresivamente más sofisticados ha permitido una adecuación a la demanda urbana, permanente y concentrada en lugares distintos de aquellos donde tradicionalmente se han obtenido o elaborado los alimentos. De ahí que las fábricas hayan pasado a contribuir en mayor medida al producto alimentario final (Velarde Fuertes, 1977; Juan i Fenollar, 1978; Maceda Rubio, 1984).

Al mismo tiempo, la extensión de las redes de comercialización y la integración de los mercados, vinculadas a los avances técnicos e infraestructurales emanados de la revolución industrial, han conllevado una especialización productiva regional: cada territorio ha orientado su actividad agraria a las producciones para las que, por sus condiciones naturales, está mejor preparado. La población de muchos espacios con vocación ganadera opta entonces por atender la demanda de materia prima de la industria agroalimentaria tratando de asegurar la venta de su producto, a costa de generar una importante transformación en los usos y estructuras tradicionales del campo. En el caso de la producción de leche, se sustituyen los espacios dedicados a cultivos de cereal, legumbres y otros productos otrora destinados al consumo familiar y al mercado local por terrenos reservados a la alimentación del ganado de aptitud lechera (Fernández García y Rodríguez Gutiérrez, 1992 y 1993; Zorita Tomillo, 2001). Del mismo modo, se persigue un aumento de los rendimientos de las explotaciones y una mejora de la calidad del producto mediante la introducción de nuevas razas y la selección genética, el incremento de la estabulación, la mecanización y la mejora de la infraestructura, entre otros medios y procedimientos que exigen fuertes inversiones apoyadas a menudo por créditos (Langreo Navarro, Soria Gutiérrez y Rodríguez-Zúñiga, 1988; Segrelles Serrano, 1991 y 1999; Espejo Marín, 1997). La población agraria implicada en esta especialización productiva, empujada por la expansión de la industria transformadora, deja así atrás los aprovechamientos extensivos y la economía de subsistencia para integrar su trabajo en una economía de mercado en la que interviene junto a las restantes actividades que participan directa e indirectamente en la elaboración y distribución de los alimentos, incluidas las que proporcionan maquinaria, semillas, productos fitosanitarias y otros insumos al productor agrario. En esta cadena, la empresa industrial, a veces con carácter multinacional, amplias cuotas de mercado y niveles de organización más desarrollados, busca controlar a su favor el proceso de transformación agraria al integrar a los productores en sus redes de recogida, negociar el suministro de algunos medios de producción o establecer el precio de compra de la materia prima. Aspecto que tienden a contrarrestar los ganaderos ${ }^{2}$ buscando una mejora de la provisión de inputs y de la comercialización a través de fórmulas de organización como las cooperativas. Con todo, algunas explotaciones no pueden adaptarse a las nuevas exigencias en términos de productividad, beneficios, dimensión óptima y capitalización, y terminan por cesar su actividad; lo que subraya el carácter de dependencia de las relaciones que el ganadero viene a mantener (Juan i Fenollar, 1978; Langreo Navarro, 1978 y 1995; Maceda Rubio, 1984; Langreo Navarro, Soria Gutiérrez y Rodríguez-Zúñiga, 1988; García Pascual, 1993; Feo Parrondo, 1997; Segrelles Serrano, 1999 y 2000).

En este artículo se estudia la transformación de las explotaciones y de los espacios ganaderos asturianos que, influidos por el desarrollo de la industria láctea, iniciaron el camino de la especialización productiva reorientando su actividad a la producción de leche. Se analiza de modo particular el ejemplo de Carcedo y Muñás, dos parroquias del actual concejo de Valdés ${ }^{3}$ ubicadas en los valles afluentes del bajo Esva (litoral occidental de Asturias) que afrontaron este proceso poniendo en marcha una iniciativa pionera de cooperativismo agrario en Asturias. El interés de las transformaciones en la organización socioeconómica de estas entidades, motivadas por el fenómeno agroalimentario señalado, justifica la

\footnotetext{
2 Ante la situación de dependencia de la ganadería intensiva, algunos autores como Segrelles (2000) aluden a la corriente que apuesta por una actividad agropecuaria sostenible apoyada en el aprovechamiento de la vegetación espontánea renovable y de las razas de ganado autóctono, lo que no ha de ser incompatible con los avances técnicos, sanitarios y económico-financieros si se adecúan convenientemente a los ecosistemas en los que se trabaja. En este sentido, es igualmente interesante la consideración de Zorita (2001) acerca de la investigación española en el ámbito de la producción animal, deficientemente conducida, según el autor, «respecto a las necesidades y posibilidades del propio país». Su estudio llama la atención sobre «el desconocimiento de los sistemas tradicionales de producción animal, bien adaptados a las condiciones naturales del país y que fueron un factor esencial en el origen y mantenimiento de medio natural en España, es decir, de los paisajes y agroecosistemas ibéricos». La insuficiente investigación de éstos generaría, de acuerdo con Zorita, una falta de actualización y mejora que llevaría a la ganadería tradicional extensiva a un proceso de regresión y desaparición, condicionando, al tiempo, la transformación del medio rural.

${ }^{3}$ Corresponde al municipio asturiano de Valdés, así denominado históricamente y en tiempo reciente, aunque con el nombre de su cabecera, Luarca, entre 1909 y 1985. En el presente artículo se utiliza esta última denominación por estar vigente en el período estudiado.
} 


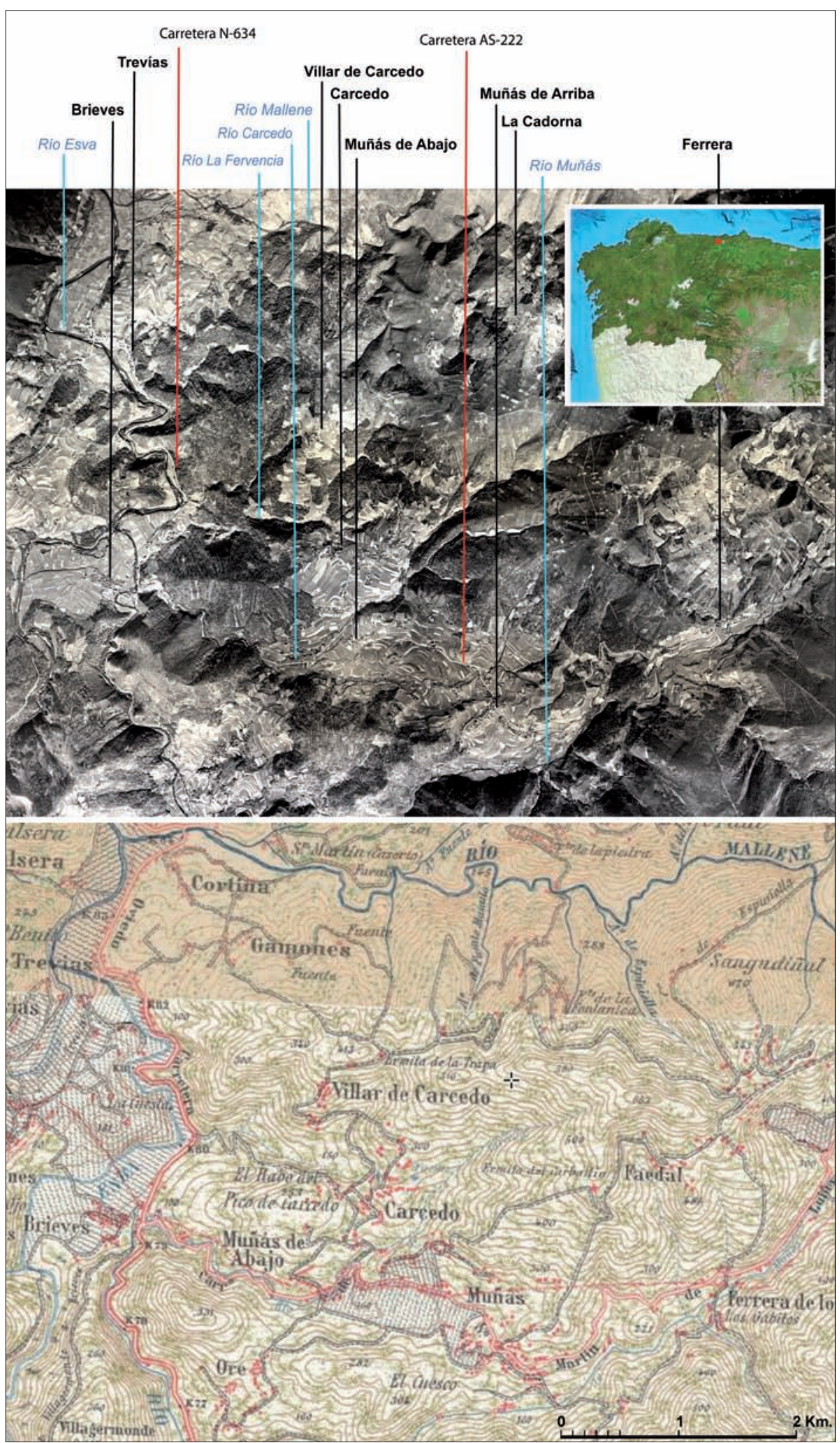

FIG. 1. Localización del área de estudio en la primera edición del Mapa Topográfico Nacional a escala 1:50.000 (montaje de fragmentos de las hojas 12 Busto y 27 Tineo correspondientes a 1940 y 1941 respectivamente) (abajo), y en el fotograma 29.001 de la denominada serie B (vuelo americano), tomado el 13 de octubre de 1956 (arriba). En el recuadro superior derecho se indica, en color rojo, la situación de las parroquias de Carcedo y Muñás sobre la imagen del noroeste peninsular proporcionada por el IGN en su visor Iberpix. 
elección del ámbito geográfico de estudio. Respecto al marco cronológico abarcado, si en el caso del conjunto regional se recorre brevemente la evolución de la relación entre las actividades agropecuaria e industrial desde las primeras experiencias de transformación láctea en fábricas (siglo XIX), con especial atención a la recuperación y posterior consolidación del sector lácteo tras la guerra civil, el punto de partida del estudio de Carcedo y Muñás se sitúa en la década de 1960 por haber marcado el inicio de su especialización productiva. En todo caso, el cierre del marco temporal coincide con la entrada de España en la Comunidad Económica Europea. La adaptación al Mercado Común, con una fuerte competencia de los espacios ganaderos continentales y el establecimiento del sistema de cuotas, entre otros elementos, han condicionado en las últimas décadas el vínculo entre ganadería e industria, endureciendo las condiciones de viabilidad de las explotaciones y generando una recesión importante de la actividad pecuaria; fenómeno, éste último, de suficiente envergadura y complejidad para abordar en un estudio específico.

\section{EL EFECTO DE LA TRANSFORMACIÓN LÁCTEA EN LA ACTIVIDAD GANADERA ASTURIANA}

La industria láctea asturiana debe su origen y su evolución inicial, en el siglo xIx y primer tercio del xx, al desarrollo técnico y a las transformaciones socioeconómicas, demográficas y territoriales resultantes de la revolución industrial. Numerosos avances tecnológicos aumentaron la eficacia, la rapidez, el volumen de tratamiento y la diversidad de los procesos de manipulación de la leche. Permitieron la diversificación de la gama de alimentos y alargaron los tiempos de conservación. En el mismo contexto, el crecimiento de la población asturiana y su redistribución geográfica, debido a la industrialización, originaron un incremento del consumo urbano (Velarde Fuertes, 1977; Maceda Rubio, 1984; Fernández Cuesta y Fernández Prieto, 1999; Fernández García, $2000 a$ y 2000b; Sevilla Álvarez, 2009). De ahí la puesta en marcha de numerosas iniciativas empresariales en esta rama de actividad, sobre todo para la fabricación de manteca y queso, que resultó favorecida por las mejoras de los transportes y de las comunicaciones al reducirse notablemente los costes de producción, abastecimiento y distribución. En general, se agilizaron las operaciones de índole económica y fue posible constituir redes comerciales extendidas por toda la Península, los archipiélagos e Hispanoamérica (Nadal Oller, 1977; Velarde Fuertes, 1977; Quirós Linares, 1985; Langreo Navarro, 1995; Suárez Álvarez, 2003).

El prestigio adquirido por la calidad del producto, muy apreciado en determinadas plazas peninsulares y ultramarinas, la estrategia de comercialización y la imagen de marca permitirían alcanzar resultados económicos muy positivos a un grupo de empresas que se situaron desde época temprana a la cabeza de esta rama de negocios (Gil y Llana, Hijos de Vicente Velarde, González y Tablado, Arias, entre otras). Los beneficios les permitieron invertir en la expansión de su red de distribución asî como en la construcción de nuevas fábricas en lugares aptos para el aprovisionamiento de materias primas, en pequeños núcleos rurales o en capitales de municipios de economía agroganadera; pero, cada vez más, al llegar al siglo Xx, en lugares más accesibles a los mayores mercados, a los centros de consumo urbano, persiguiendo beneficiarse, además, de economías de aglomeración (Quirós Linares, 1985; Langreo Navarro, 1995; Suárez Álvarez, 2003).

El crecimiento de estos negocios industriales requería aumentar y extender el acopio de materia prima, innovar en los métodos de recogida y modificar la frecuencia de ésta aprovechándose de las mejoras de la red viaria. De ahí que las empresas pasaran de recoger producto artesanal a abastecerse de nata y de leche líquida, al tiempo que las caballerías daban paso al transporte motorizado. Todo ello supuso una evolución de las relaciones con los suministradores hasta provocar la reorganización de la actividad campesina con el fin de adaptarla a las necesidades de las empresas transformadoras. Impulsada por el desarrollo de la industria, avanzado el siglo XIX y de manera muy lenta, la ganadería conocerá incipientes cambios higiénico-sanitarios, y zootécnicos en lo relativo a la selección de las reses, el régimen de mantenimiento, las condiciones de estabulación, la alimentación, el sistema de ordeño o la conservación de la leche en las explotaciones, entre otros aspectos. Los organismos oficiales incentivan además las transformaciones y, por tanto, participan de la evolución señalada. Se apunta entonces a una reorientación en el modelo de explotación agraria hacia la producción de leche en buena parte de los valles y la marina, en un proceso que no cristaliza en Asturias, sin embargo, hasta bien entrada la segunda mitad del siglo xx pues la guerra civil y sus efectos económicos y territoriales negativos interrumpen la modernización ganadera (Ferrer Regales, 1963; García Fernández, 1975; San Miguel Cela, 1977; Ocampo Suárez-Valdés, 1991; Maceda Rubio, 1992; Inclán Suárez, 1999). 


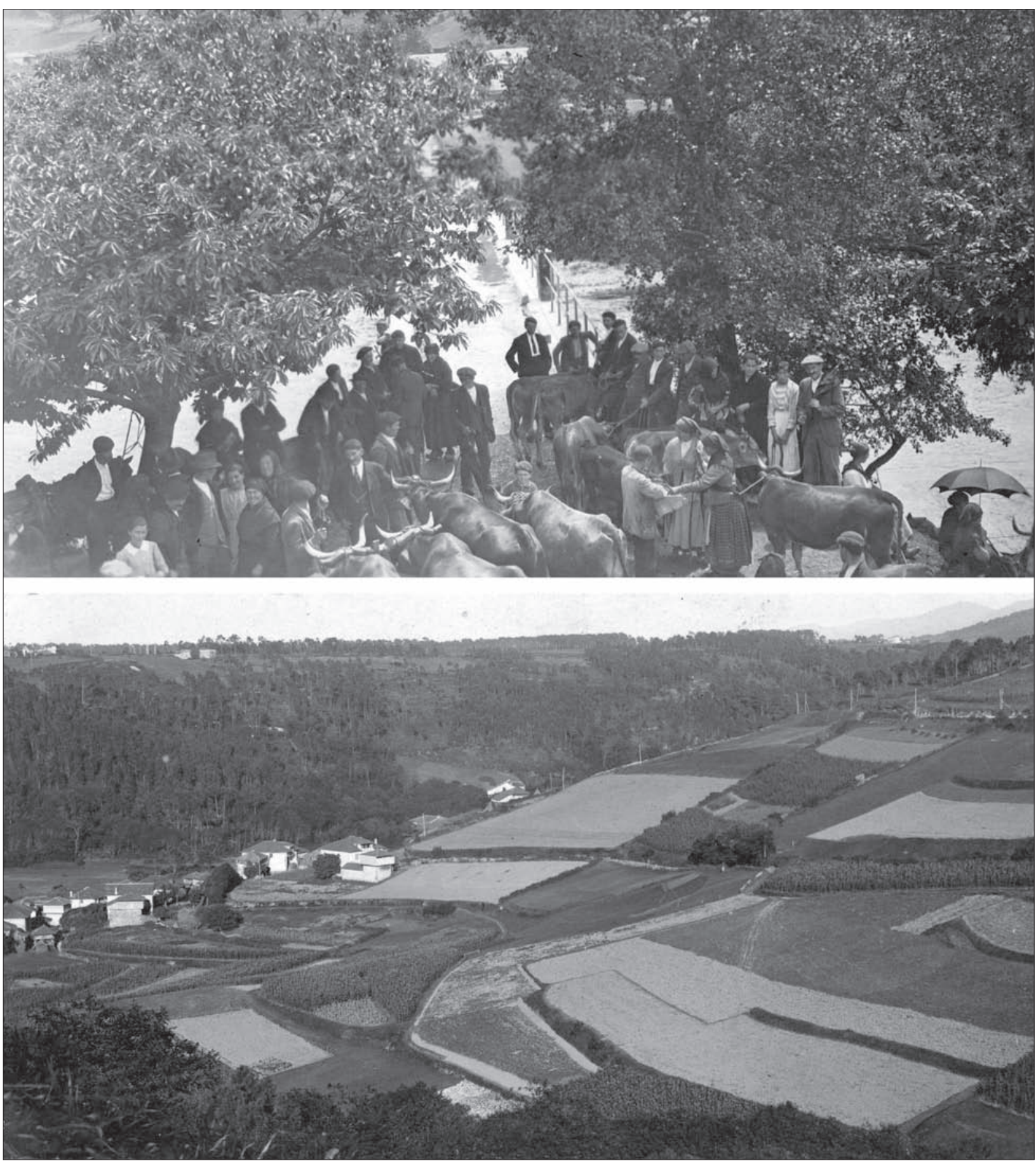

FIg. 2. En la imagen superior, aspecto parcial de la feria de ganado en Trevías (Luarca) hacia 1925. Celebrado en el mayor núcleo de población del valle del Esva, este certamen mantiene su vigencia cuatro décadas más tarde, cuando la especialización de las explotaciones ganaderas en la producción de leche se generaliza en la marina y en los valles del litoral asturiano. Hasta entonces, el ganado de raza autóctona y la dedicación del terrazgo a cultivos de cereal y huerta para el autoconsumo y los mercados locales, en el contexto de una economía de subsistencia, son predominantes en el espacio agrario valdesano. Este paisaje característico del sistema agrario tradicional se percibe en la localidad de Cueva, junto a la desembocadura del Esva, en la misma fecha (imagen inferior). Fuente: Fondo El Progreso de Asturias, Museo del Pueblo de Asturias (Gijón). Fotografía de autor anónimo. 


\section{LA RECUPERACIÓN DE POSGUERRA}

La guerra civil detuvo las transformaciones agrarias iniciadas tímidamente en el siglo anterior y ocasionó la vuelta a la economía campesina de subsistencia y al autoconsumo. A la alteración de los flujos de capitales, mercancías y personas se unió la que ejercieron los bandos contendientes, en su ejercicio de control del territorio, condicionando los tipos de productos lácteos fabricados para abastecer a la población (Langreo Navarro, 1995). La recuperación posterior no fue fácil habida cuenta del principio de autarquía en que se apoyó la política económica impuesta en los primeros tiempos de la dictadura franquista. Se estableció un control rígido a la importación que limitó las innovaciones técnicas y, por tanto, el crecimiento industrial debido a la dificultad para adquirir consumos intermedios y bienes de equipo. Además, con el fin de asegurar el abastecimiento de alimentos a la población en un período de acentuada escasez, el Gobierno decretó una férrea intervención que afectó a la fabricación y al comercio de productos lácteos. El descenso del poder adquisitivo de la población y la consecuente disminución del consumo tampoco ayudaban a la recuperación (Ministerio de Industria y Comercio, 1944, $1945,1946 a$ y $1946 b)$.

De acuerdo con los datos ofrecidos por el Censo de la Licencia Fiscal de la Cámara de Comercio de Oviedo y el catálogo oficial de la Exposición de Gijón de 1946, había a mediados de la década en Asturias al menos 49 empresas propietarias de 31 fábricas de queso, 22 de manteca, cuatro mixtas de queso y manteca y dos de leche condensada. Su localización en pequeños núcleos de parroquias rurales continuaba siendo frecuente. Aunque se localizaban ya más establecimientos en las capitales municipales y en las cabeceras comarcales, además de algunos en las ciudades. Respecto a la distribución geográfica, la industria láctea estaba más asentada en el litoral oriental, en la cuenca del Piloña y en el centro de la región, áreas en las que, además, la modernización de la ganadería conocía resultados más tempranos.

En Llanes se encontraban las queseras Juan Gavito, Juan Inés y Diddens, además de las mantequeras de Sadi y del propio Juan Inés Blanco; al tiempo era novedad en el ala oriental de la región la puesta en marcha de una fábrica de leche condensada en Bustio (Ribadedeva). Entre esta zona, especialmente dinámica, y el área central de Asturias se alineaban otros establecimientos en los concejos del surco prelitoral Oviedo-Parres, beneficiándose del paso de la carretera nacional N-634 y de los Ferrocarriles Económicos: los de la familia Valle en Infiesto (Piloña),
Reunión de Industrias Lácteas (RILSA) en Sevares (Piloña) y Juan Martínez en Marcenado (Siero), entre los más destacados. En los municipios del área central consolidaron su actividad la Mantequera de Amandi (Villaviciosa), Mantequerías Arias (Oviedo), La Lechera de Cancienes (Corvera) y Mantequerías Riera (Gijón). Por su parte, en el centro-occidente y occidente asturiano se mantenían algunos lugares tradicionales en la producción de derivados lácteos en los concejos de Pravia, Salas, Tineo y Luarca, aparte de otros dispersos por diferentes municipios. La Mantequera de Tineo se encontraba entre las principales productoras y comercializadoras del occidente, al tiempo que el establecimiento de una de las ramas de los Arias, la de Antonino Arias, que trabajaba desde Corias (Pravia), perdía influencia en este periodo (Cámara Oficial de Comercio, Industria y Navegación de Oviedo, 1946; Catálogo oficial de la Exposición de Productos Regionales del Noroeste de España, 1946; Langreo Navarro, 1995).

Mientras tanto, el negocio Ángel Arias, que operaba con sede central en Oviedo, mantenía su posición entre las firmas más relevantes del sector ${ }^{4}$. Había transformado los sistemas de aprovisionamiento de materia prima en los años veinte con su red de desnatadoras y basaba su estrategia en la expansión de las instalaciones y en la concentración de áreas de recogida. Sostenía económicamente la ampliación de su área de influencia merced a los beneficios de las actividades comerciales de la empresa, que contaba con una red de distribución y venta de mucho prestigio en todo el país. La primera expansión de posguerra de esta empresa tuvo lugar a comienzos de los años cuarenta con la compra de una antigua fábrica en Medina de Rioseco (Valladolid) para elaborar queso a partir de leche de oveja. Y en Asturias puso en marcha otra planta quesera en 1945, concretamente en Arriondas. Arias aprovechaba, de este modo, la accesibilidad proporcionada por el ferrocarril de vía estrecha y la red principal de carreteras. Precisamente en esta zona se dejaban notar por ese tiempo algunos de los primeros síntomas de recuperación del proceso de modernización ganadera y de especialización lechera.

Debe tenerse en cuenta que en el año siguiente a la finalización del conflicto se mantenía en Asturias una cabaña ganadera con predominio del vacuno de aptitud mixta (Fernández García y Rodríguez Gutiérrez, 1993). El Anuario Estadístico de España contabiliza en esa fe-

\footnotetext{
${ }^{4}$ La información relativa a la historia de las empresas de la familia Arias ha sido facilitada por D. Juan Revuelta Arias, bisnieto de los fundadores y ex asesor jurídico de la empresa.
} 
cha 201.223 cabezas de bovino en Asturias, de las cuales el 54,6\% (109.974 reses) se dedicaba a trabajo y ordeño, el $22 \%$ (44.332) a carne y ordeño, el 12,8\% (24.504) sólo a trabajo, mientras que las especializadas en leche o en carne representaban el 5,9\% (11.885) y el 5,23\% (10.527) respectivamente. La producción de leche acusaba además una disminución fuerte con respecto a los años previos al conflicto. Había experimentado anteriormente un crecimiento muy notable que llevó a pasar en el conjunto del país de 1.331 millones de litros en 1929 a casi 1.453 en 1933 (subiendo el 8,4 \%); aunque en Asturias se limitó al $4 \%$, de 248,7 millones de litros en 1929 a 259,1 en 1933. Sin embargo, dos años después del final de la guerra la cifra caía hasta 256,4 millones de litros en la provincia. Por otro lado, el reparto de utilidades de la leche evidenciaba el letargo de las prácticas ganaderas asociadas al proceso industrial: 226 millones para consumo directo $(88,1 \%), 14,5$ millones para la fabricación de quesos $(5,6 \%), 10,9$ millones para la de manteca $(4,2 \%)$ y 5 millones de litros exportados al resto de España $(1,9 \%)$. La proporción de los prados artificiales y los forrajes sobre el total de la superficie cultivada según el Anuario era del $6 \%$ (10.241 ha) en 1941. Y la superficie correspondiente a las praderas y a la alfalfa disminuía con respecto a 1935 (960 ha frente a 965 ha y 850 ha frente a 970 ha, respectivamente) (Dirección General de Estadística, 1943). El tradicional policultivo de subsistencia mantenía una presencia notable en el terrazgo (Fernández García, Maceda Rubio y Rodríguez Gutiérrez, 1990).

La Junta Provincial de Fomento Pecuario retomó en esa época la divulgación agropecuaria, la celebración de concursos y exposiciones y la aplicación de técnicas de selección del ganado. Se encargaba, por ejemplo, de organizar y reglamentar el funcionamiento de las paradas de sementales autorizadas, donde se llevaba el registro de las montas y los nacimientos. Se ocupaba asimismo de localizar y eliminar las paradas clandestinas. Y reforzaba la difusión de las enseñanzas agropecuarias con la publicación de un boletín informativo y la organización de conferencias y jornadas sobre alimentación ganadera. Además, la Exposición Provincial de Ganados se continuó celebrando, una vez concluida la guerra, con la novedad de pruebas funcionales de leche y grasa, y de pruebas genealógicas. La Junta establecía las normas zootécnicas a las que se sujetaban sus programas y reglamentos así como los de los concursos de Oviedo y Llanes, elogiados por la Dirección General de Ganadería debido a su mejora. Con todo, la Junta no logró acometer todas las actividades deseadas debido a la falta de financiación dado que era un organismo autónomo. Aprovechaba algunas colaboraciones económicas modestas de la Dirección General de Ganadería, aparte de una subvención de la Diputación (Ochoa Uriel, 1946).

En Llanes, donde las innovaciones tuvieron mayor incidencia debido a su proximidad a la provincia de Santander (con más tempranas innovaciones por ser destacada abastecedora de Madrid), la Feria de Ganado fue sustituida en 1940 por el Concurso-Exposición de Ganados e Industrias Derivadas. Su planteamiento, diferente al de la Feria, incidía en la orientación funcional. A la calificación morfológica, funcional y genealógica de las reses expuestas se unían las pruebas de rendimiento lechero. La celebración de estos concursos, junto a la de los que tenían lugar en Santander y Reinosa, se vinculó a los Servicios de Libros Genealógicos, creados para mantener un registro actualizado del ganado seleccionado. En Asturias funcionaban con la colaboración de las Juntas Locales de Fomento Pecuario, siendo la de Llanes la primera en ocuparse de estas tareas. En 1942 inició la inscripción de las reses bovinas y el control del rendimiento lechero. No obstante, las inscripciones anteriores a 1945 no fueron muy numerosas, como demuestra que en el Servicio Provincial de Libros Genealógicos de Oviedo en esa fecha hubiera inscritos únicamente 904 ejemplares de razas holandesa, suiza, asturiana de los valles y casina. De ellos, 223 correspondían al registro efectuado en Llanes (Ferrer Regales, 1963).

Otra de las entidades implicadas en el fomento agropecuario fue el Servicio de Agricultura y Ganadería de la Diputación Provincial de Asturias. Apoyándose en el Presupuesto Extraordinario para el Resurgimiento de la Riqueza Provincial, puso en marcha un plan de creación de centros experimentales comarcales que, atendiendo a la especificidad de cada zona geográfica dentro de la región, complementara la actividad de las ya existentes granjas de La Cadellada (Oviedo) y Tineo, dedicadas a la mejora en la selección y en la alimentación del ganado schwyz y del frisón. A través de un consorcio con el Instituto Nacional de Colonización se inició en los años cuarenta la primera parte del plan con el fin de crear cinco granjas-escuelas en los concejos de Siero, Villaviciosa, Llanes, Avilés y Cangas del Narcea (Diputación Provincial de Asturias, 1946). En 1946 ya se contaba con terrenos en Avilés y se había inaugurado la granja de Siero. Las instalaciones constaban de establos para las reses, estercolero, cochiqueras, conejeras, sección de apicultura, observatorio meteorológico y un aula para enseñanzas agropecuarias. Funcionaba además una parada de sementales en la que se obtenían los ejemplares que debían 
cubrir la red de paradas protegidas por la Diputación, con la que se garantizaba la disponibilidad en las áreas localizadas fuera del radio de influencia de las granjas. Con todo, pese a contar pronto setenta sementales que realizaban 13.000 servicios anuales, las solicitudes superaban la oferta de animales de la granja de Siero. De ahí que se decidiera vender a los responsables de las paradas algunas hembras de razas seleccionadas para que, aplicando las técnicas apropiadas, obtuviesen sus reses reproductoras. La venta de ganado selecto se destinó igualmente a los ganaderos. Se conoce la llegada de, al menos, tres lotes para la venta en los años cuarenta: el primero, en 1941, de la raza schwyz; un año más tarde, procedente de Holanda, se importó un lote de ganado frisón; y cuatro años después, de nuevo desde Suiza, llegaron ejemplares para las explotaciones asturianas.

El Servicio de Agricultura y Ganadería de la Diputación también se preocupó por la celebración de cursillos anuales; cometido en el que se involucró asimismo la Cámara Oficial Sindical Agraria (COSA) eligiendo temáticas como praticultura y cultivos forrajeros, prácticas ganaderas e industrias lácteas (Inclán Suárez, 1999). El resultado de estas acciones parecía dejarse notar en la región cantábrica al finalizar la década de los cuarenta. Al llegar a 1949 la superficie ocupada por las praderas artificiales y los forrajes alcanzaba 50.948 ha entre Asturias y Santander (Dirección General de Estadística, 1952).

\section{LA CONSOLIDACIÓN DE LA INDUSTRIA LÁCTEA} Y LA MODERNIZACIÓN DE LA GANADERÍA DE LECHE

El desarrollo del sector lácteo se aceleró en Asturias a partir de la década de 1950 con el funcionamiento de aquellas empresas que desde la época anterior disfrutaban de una posición destacada, como Arias y RILSA, y además con el protagonismo creciente de otras implantadas en la región entre la década señalada y la de 1980: Industrias Lácteas Asturianas (Ilas)-Reny Picot, Central Lechera Asturiana (Clas), Nestlé y Danone, principalmente. Además de atender las tradicionales producciones de quesos y mantecas, los nuevos establecimientos de transformación láctea se ocuparon cada vez más de otros productos como la leche en polvo, la leche condensada, la leche líquida para el consumo, el yogur, etc. Ferrer Regales contabiliza setenta y cinco empresas en 1959 (Ferrer Regales, 1963) y en el Censo de la Licencia Fiscal de la Cámara de Comercio de Oviedo aparecen inscritas 77 fábricas en 1961, frente a las 59 existentes en 1946 (Cámara Oficial de Comercio, Industria y Navegación de Oviedo, 1961). Las instalaciones se ubicaban fundamentalmente en la mitad norte de la región, con mayor concentración geográfica en los concejos de Llanes, Villaviciosa, en los alineados a lo largo del surco prelitoral Oviedo-Parres y en los situados en la cuenca del Narcea. No obstante, al margen del número de instalaciones, valorando el volumen de cuota pagada al Tesoro, observamos diferencias empresariales importantes, más acentuadas que décadas atrás. Puede interpretarse como un desequilibrio en la capacidad de inversión que anuncia un proceso de concentración empresarial. Si a finales de los años cincuenta Arias y RILSA acaparan buena parte del acopio de leche cruda, la competencia se recrudece años más tarde con la penetración de Nestlé. En 1963 controlaba ya 30 de los 207 puestos de recogida del oriente de la región, mientras que RILSA tenía 47 y 54 correspondían a Mantequerías Arias (Ferrer Regales, 1963). En pocos años crecería también la presencia de Ilas-Reny Picot, creada en Anleo (Navia) en el inicio de la década.

Empezaba a languidecer el peso de las producciones de empresas medianas y pequeñas, muchas de ellas mantequeras y queseras, teniendo que ver en ello, además, que algunas de las grandes transformadoras como IlasReny Picot incluían la mantequilla o el queso entre sus principales producciones. Y al llegar a los años setenta se percibe más claramente la concentración: sirva de ejemplo la compra de la estructura de RILSA por parte de Nestlé (Langreo Navarro, 1995); a lo que se sumaría la compra de la infraestructura de recogida de Clesa por parte de Danone, también a finales de los setenta como paso previo a la puesta en marcha de la fábrica de Salas (1981), especializada en Petit Suisse. En ese momento el número de establecimientos ya había descendido por debajo del medio centenar y el de empresas era ligeramente menor dado que varias poseían más de una fábrica: por ejemplo, Nestlé tenía cuatro localizadas en Luarca, Villaviciosa, Piloña y Grado (Maceda Rubio, 1984). De acuerdo con el estudio de Pañeda Fernández (1981), existían a comienzos de la década de los ochenta en Asturias 47 establecimientos y 44 empresas, de las cuales las seis mayores recogían el $82,2 \%$ de la leche tratada y concentraban el $87,6 \%$ de la producción. Por lo general, eran también las que más diversificaban; por ejemplo, Nestlé llega a fabricar en Villaviciosa leche envasada, leche condensada, leche en polvo, queso de tipo duro y queso fundido (Maceda Rubio, 1984). Aumentaba, en definitiva, el consumo de leche higienizada y derivados lácteos en Asturias: el promedio de 64,4 kg/hab./año calculado en 1965 se doblaba al llegar a 1981 con 131,8 kg/hab./año (Pañeda Fernández, 1981). 
Las fábricas, sin alejarse de las áreas productoras de leche, comenzaron a buscar en mayor medida la proximidad a los principales mercados. Los establecimientos de tamaño modesto seguían localizándose mayoritariamente en las cabeceras municipales, en el entorno de éstas o en parroquias más alejadas. Y algunos de tamaño medio tenían ya asiento en ciudades; por ejemplo, Mantequerías Riera, Industrias Granderroble y Granja La Luz poseían sede en Gijón. Por otro lado, entre las firmas más pujantes primaba el acercamiento a la periferia de las ciudades, en zonas de uso industrial en los casos de centros vinculados a la reordenación estatal del proceso de higienización de la leche y de suministro eficiente a la población de las ciudades, concretado desde 1952 en la creación de una o varias centrales lecheras en los municipios con más de 25.000 habitantes (Presidencia del Gobierno, 1952; Ministerio de la Gobernación y Ministerio de Agricultura, 1952). Así sucedió con Central Lechera Asturiana (Granda, Siero), La Polesa (Granda, Siero) y Lagisa (Porceyo, Gijón). Se veían favorecidos en este caso por la cercanía a los centros de consumo, pudiendo afrontar, merced a su capacidad de inversión, una recogida extensa y más alejada del lugar de tratamiento industrial (Maceda Rubio, 1984). El mismo tipo de localización tenía Mantequerías Arias en su fábrica principal, trasladada de Oviedo a Vegalencia (Ribera de Arriba) en 1971. Por su parte, Lactavisa utilizaba este modelo en la margen izquierda de la ría de Avilés. Distinto sería el caso de Nestlé y Danone en municipios del centro-oriente y del centro occidente, o de Ilas en la marina occidental.

Para entender el crecimiento del sector lácteo referido más arriba es importante aludir a la implantación en esta época de un nuevo sistema de organización socioeconómica y territorial en Asturias. La actividad industrial recibe un nuevo impulso en el centro de la región de modo que la población se concentra en los núcleos urbanos originando un retroceso de la población agraria y la ruptura definitiva de la organización tradicional del espacio rural. Aumenta así la población urbana consumidora de productos lácteos en proporciones desconocidas desde el siglo anterior y se aceleran las transformaciones en el campo, optando buena parte de las explotaciones de los valles y de la marina por la especialización lechera (Fernández García, 1990; Fernández García y Rodríguez Gutiérrez, 1992 y 1993; Rodríguez Gutiérrez, 1996; Lorenzi, 2004). En ese contexto se identifican como retos para la modernización agraria la mejora de los rendimientos y el aumento de la capacidad de inversión de los ganaderos (Caja de Ahorros de Asturias, 1969), muchas veces impedidos por el minifundismo y la excesiva parcelación. La adecuación de la ganadería a la demanda de la industria alimentaria venía a suponer al campesinado asturiano unas condiciones que le colocaban en una situación de dependencia de las empresas transformadoras (Fernández García, Maceda Rubio y Rodríguez Gutiérrez, 1990).

Otro rasgo del proceso es la continuidad en la implicación de las instituciones públicas, tanto del Estado como provinciales y locales, en la investigación agropecuaria, la difusión de nuevas prácticas, la divulgación y la formación permanente. Resultado de esta preocupación fue la apertura de un bachillerato laboral superior en la modalidad agrícola-ganadera con la especialidad de industrias lácteas (Ministerio de Educación Nacional, 1960). O la distribución de semilla para la siembra de praderas artificiales, costeada por el Ministerio de Agricultura en un $80 \%$. La red de paradas de sementales mantenía su actividad y la de inseminación artificial lograba resultados notables, aumentando entre 1960 y 1969, por ejemplo, el número de reses inseminadas de 35.242 a 105.974. En ese periodo el Servicio de Libros Genealógicos y Comprobación del Rendimiento registraba más de tres mil cabezas y elevaba el rendimiento lechero anual por res muy por encima de 3.000 kilogramos. Aunque el rendimiento medio del ganado vacuno asturiano no registrado en este Servicio era bastante menor. El mismo organismo, con sedes en Llanes, Cangas de Onís, Parres, Oviedo, Gozón, Avilés, Luarca y Navia promovía la importación de ejemplares de raza frisona y pardo-alpina.

El Estado tuvo un papel importante en la evolución de la cabaña y el fomento de la selección del ganado a través de iniciativas como la creación de los Núcleos Selectos de Expansión Ganadera y la compra de ganado con el fin de distribuirlo entre titulares de explotaciones, paradas de sementales y centros de inseminación. Así, al llegar a finales de la década de 1960 había en Asturias 633 machos sementales, 18.292 vacas de ordeño suizas y 85.294 holandesas, según datos de la revista Campo Astur. Órgano de la Cámara Oficial Sindical Agraria $y$ de sus Hermandades de Labradores y Ganaderos. Y su distribución geográfica era heterogénea: el occidente interior y el oriente interior tenían menor densidad ganadera y mayor presencia de razas autóctonas asturianas. Mientras que en el litoral oriental y en el centro de la región se dejaban notar los cambios ganaderos en mayor medida, en el primer caso por el contacto con Santander, provincia avanzada en estas cuestiones, $\mathrm{y}$ en el segundo por el estímulo del abastecimiento a los mercados urbanos sumado a las acciones de las estaciones agropecua- 
rias y los centros de experimentación. Influiría en el área central el funcionamiento de las centrales lecheras de Porceyo y Granda, como lo haría en el litoral occidental el crecimiento de Ilas-Reny Picot y la recogida de otras grandes empresas.

Hubieron de superarse, no obstante, problemas relacionados con la calidad de la leche que podían encontrar solución por la vía de la inversión en las explotaciones. Debían generalizarse los sistemas de ordeño automático y la instalación de tanques de refrigeración, gravosos para unos ganaderos sujetos a precios de la leche poco remuneradores. La aplicación del decreto de Centrales Lecheras en Asturias, con requisitos higiénico-sanitarios (Presidencia del Gobierno, 1967a, 1967b y 1968; Langreo Navarro, 1995), la constitución de Central Lechera Asturiana como sociedad de transformación con carácter cooperativo y la pujanza de las nuevas empresas transformadoras contribuiría a partir de 1970 a la penetración de innovaciones tecnológicas en el campo. Se crearon los primeros centros de recepción y enfriamiento de leche en las comarcas por las que se extendían las redes de aprovisionamiento de materia prima. Asimismo, se empezaron a utilizar camiones cisterna para el transporte a las unidades de producción y se incentivó la instalación de sistemas de ordeño mecánico y tanques de frío a través de programas de financiación al ganadero.

La aplicación de las medidas y avances señalados llevó a una progresiva integración de la ganadería en la economía de mercado que se tradujo, entre otros indicadores, en el aumento de las reses de ordeño: 220.464 en 1985 , con mayoría de raza frisona y una producción total de leche de más de 741 millones de litros, de los cuales 580 eran comercializados a través de industrias lácteas. En esa fecha, los prados ocupaban 242.193 ha, los pastizales se extendían sobre 84.923 ha y el erial a pastos alcanzaba 158.852 ha (Consejería de Agroganadería y Recursos Autóctonos, 1985).

\section{EL CAMINO HACIA LA ESPECIALIZACIÓN LECHERA EN EL LITORAL OCCIDENTAL DE ASTURIAS: EL EJEMPLO DE LAS PARROQUIAS DE CARCEDO Y MUÑÁS (CONCEJO DE LUARCA)}

En un primer momento, el territorio costero occidental de Asturias experimenta los cambios inducidos por la industria láctea con menos intensidad que el oriente y el centro de la región. Desde el punto de vista de la permeabilidad a las transformaciones agrarias señaladas, el litoral occidental constituye un territorio de transición entre las áreas oriental y central y el interior montañoso, manteniéndose más claramente en este último la vigencia el modelo histórico de aprovechamientos agrarios (Fernández García, Maceda Rubio y Rodríguez Gutiérrez, 1990). Pero a partir de 1960 algunos municipios de la costa occidental aceleran su incorporación al proceso y se colocan entre los principales productores de leche.

Ocurre así en Luarca, municipio de considerable extensión $\left(352 \mathrm{~km}^{2}\right)$ que ocupa una posición intermedia entre las cuencas de los ríos Navia, al oeste, y NalónNarcea, al este. Lo enmarcan los ríos Barayo y Cabo, a oeste y este (limitando con Navia y Cudillero, respectivamente), y la Montaña de Río Negro, la sierra de Silvallana y los montes de Castañéu, por el sur, estableciendo límite con los concejos de Villayón, Tineo y Salas. Se trata de un territorio de topografía contrastada, como buena parte del litoral de Asturias, donde mar y montaña se enfrentan en una estrecha banda que no suele alcanzar los diez kilómetros de anchura. Cerca de la costa la topografía favorece el desarrollo de una ganadería intensiva de vacuno especializada en la producción de leche, que también aparece en las vegas de los ríos y en otras áreas de los valles que se abren desde el interior montañoso, principalmente los de los ríos Negro y Esva (García Fernández, 1988; Fernández Pereiro, 1992).

Los espacios señalados aprovechan el paso de carreteras de primer orden: la N-632, con repetidos ascensos y descensos sobre los valles y vallejos que quiebran la rasa; y la N-634, que entronca con la anterior en Canero, una vez recorrida la cuenca del Esva desde el interior, y continúa su trazado costero hacia el oeste. El ferrocarril Ferrol-Gijón de vía estrecha llega a la capital municipal, en la desembocadura del río Negro, a principios de los años sesenta y se prolonga hacia Navia y Vegadeo hasta completar el trazado asturiano en 1972. Además, al avanzar la segunda mitad de la centuria, el campo luarqués se beneficia de importantes mejoras llevadas a cabo en el abastecimiento de aguas y en el alumbrado público ${ }^{5}$. En definitiva, se amplía la dotación de infraestructuras y servicios para el desarrollo de la actividad económica; lo que beneficia a las empresas de transformación láctea que trabajan a lo largo de este período en la zona.

\footnotetext{
${ }^{5}$ El propio Ayuntamiento acude al Primer Concurso de Cooperación Provincial de Obras y Servicios Municipales, convocado por la Diputación en 1955 con una ambiciosa propuesta de electrificación del municipio que busca favorecer al $70 \%$ de las entidades rurales. Gracias a estas acciones, en 1958 se había inaugurado la red en 30 lugares y se preveía su puesta en funcionamiento en otros 12 en fecha inmediata, debiendo quedar terminada la campaña en 1960-61 con una previsión de gasto de 7 millones de pesetas (González Cobas, 1960).
} 


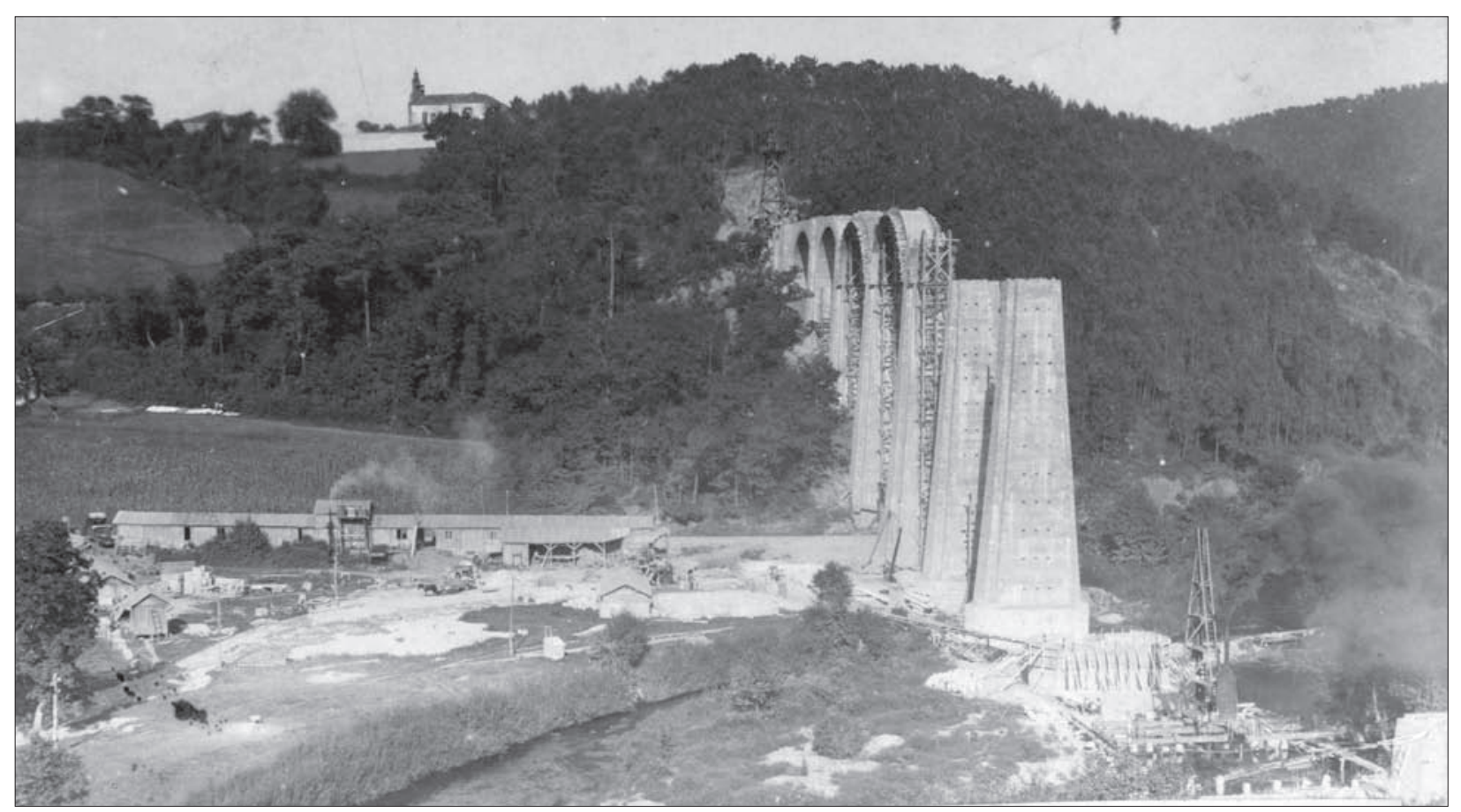

FIG. 3. La mejora de los transportes y las comunicaciones favoreció el desarrollo de la actividad económica en la costa occidental asturiana durante la segunda mitad del siglo xx. El ferrocarril Ferrol-Gijón recorre la marina en este sector litoral y salva el bajo valle del Esva en la localidad de Canero. Su viaducto, en construcción ya a finales de los años veinte sobre la vega de esta localidad, constituye una de las múltiples obras que permitieron articular la comunicación ferroviaria entre el centro y el extremo oeste de la región. Aunque la envergadura de los trabajos en todo el trayecto retrasaron la inauguración de la línea completa hasta 1972. Fuente: Fondo El Progreso de Asturias, Museo del Pueblo de Asturias (Gijón). Fotografía de Enrique Gómez.

En 1960 se dejan notar algunos síntomas de modernización de las prácticas ganaderas. En el lugar conocido popularmente como la Feria, en Luarca, se celebran concursos y exposiciones de ganado con ejemplares selectos del concejo y de todo el occidente de Asturias, siendo importante el que tiene lugar en la primera decena de agosto. También tiene repercusión el certamen celebrado en Trevías, en el valle del Esva, el segundo lunes del mes de septiembre. Además, en Barcia, sobre el tramo de rasa costera situado entre las desembocaduras del Esva y del Negro, funciona un campo de demostración agrícola adscrito a la Sección Segunda del Ministerio de Agricultura, dirigido por la Jefatura Agronómica de Oviedo con un perito agrícola del Estado al frente. Entre sus misiones se encuentran la investigación, la difusión y la enseñanza de modernas prácticas agrarias, incluyendo la organización de cursillos y conferencias en los núcleos rurales, la entrega de semillas a colaboradores para el establecimiento de praderas artificiales, el estudio de fórmulas de abonado para praderas naturales, el reparto de semillas de remolachas seleccionadas y de maíces híbridos, etc. In- tervienen en estas acciones el Plan de Ayuda Americana y el Instituto Nacional de Semillas Selectas del Ministerio de Agricultura, además de los Servicios Agropecuarios de la Diputación Provincial ${ }^{6}$.

Por otro lado, existen en la misma fecha paradas de sementales bovinos de las razas asturiana, holandesa y schwytz en los pueblos de Otur, Villuir, La Ordobaga, Boronas, San Pelayo, Piñeros, Leiriella, Paredes, Barcia, Cadavedo, Lago, Trevías, Ayones, Castañedo, Alienes, Carcedo, Busto, Muñás, Mones, Arcallana y Villanueva. Asimismo, hay centros de inseminación artificial ganadera en Luarca, Barcia, Querúas, Cadavedo, Trevías, Muñás, Villuir y Otur, que se proveen directamente de la Estación Pecuaria Regional de Somió, en Gijón.

\footnotetext{
${ }^{6}$ Según indica Modesto González Cobas en su monografía turística e histórico-descriptiva de Luarca y su concejo, el régimen alimenticio del ganado es mixto aunque con más participación de la estabulación que del pastoreo. Señala como alimento habitual la hierba, el vallico, la alfalfa, el trébol y algunos piensos (maíz y salvados, pajas y pajas de cereales).
} 


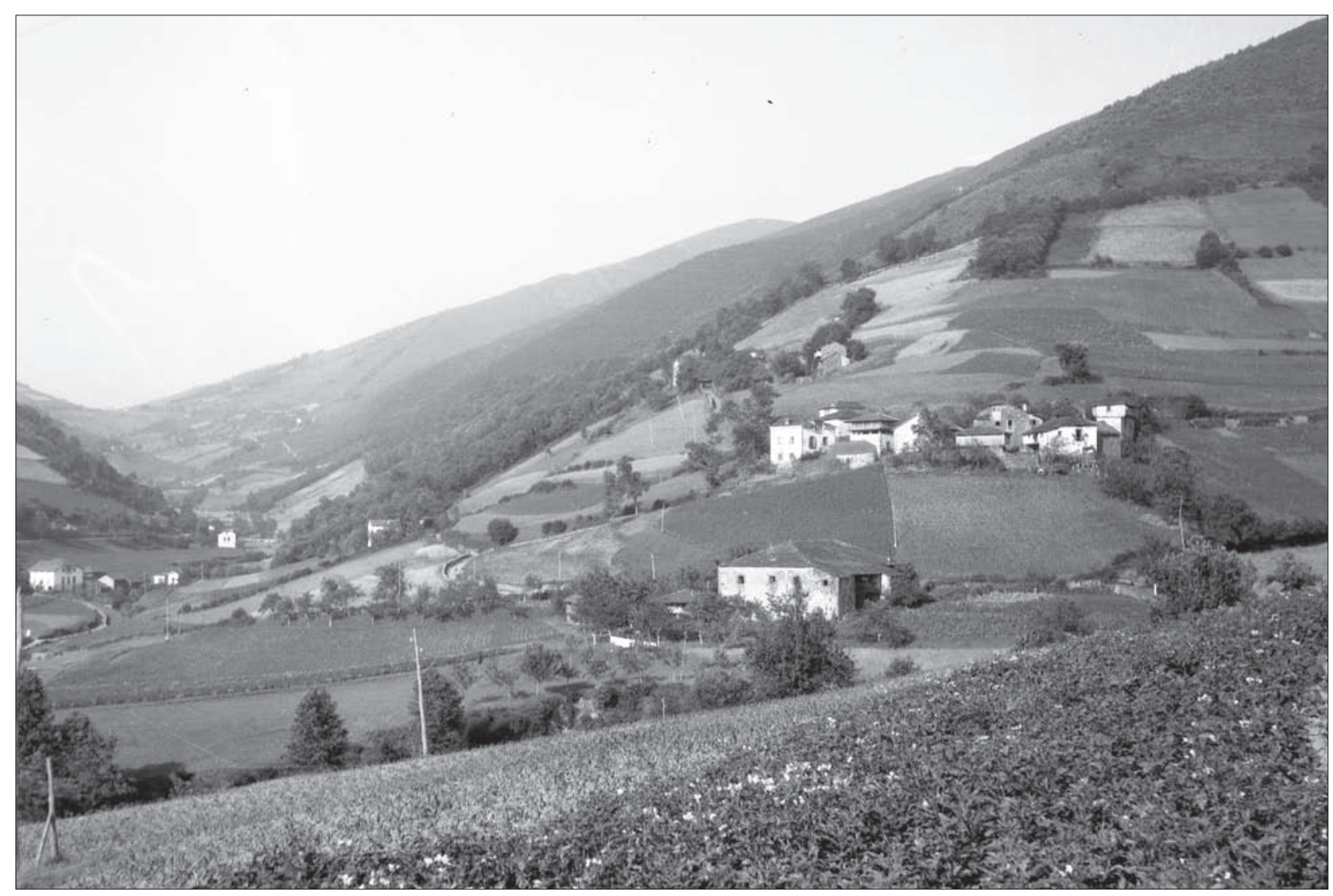

FIg. 4. Aspecto parcial de Ferrera de los Gavitos en el entorno de Casa El Palacio (valle de Muñás) en la década de 1950. La dedicación de los terrenos junto a las viviendas evidencia el mantenimiento de los aprovechamientos tradicionales: pradera natural y cultivos para consumo propio. Fuente: Fondo Foto Gómez, Museo del Pueblo de Asturias (Gijón). Fotografía de Camilo Gómez.

La ganadería ocupa, por tanto, un lugar importante en la economía municipal en 1960 . Se basa principalmente en la explotación del bovino, destacando la raza asturiana de los valles, la suiza schwytz y la holandesa, con una clara menor representación de estas dos últimas con respecto a la primera. La raza asturiana tendría entonces una dedicación mixta para la producción cárnica y lechera, si se tiene en cuenta que nueve de los quince millares de reses de vacuno son de ordeño. Su producción supera los once millones de litros anuales. Para atender su alimentación se dispone de una superficie creciente aunque discreta, condicionada por las características topográficas del territorio municipal: de las 35.372 ha de superficie total del concejo, las praderas y las tierras de labor ocupan en torno al $22 \%$ del total $(7.766,92 \mathrm{ha})$ y los pastizales apenas superan el $3 \%(1.166,95 \mathrm{ha})$ mientras que el erial a pastos bastos se extiende sobre el $11 \%$ de extensión municipal (3.840,94 ha). Los prados o praderas naturales llegan a las $4.000 \mathrm{ha}$; sin embargo, las praderas artificiales rondan solo las 300 ha. El maíz ocupa 2.000 ha y va asociado generalmente con fabas y con vallico. Del mismo modo, cuando levantan la patata (1.000 ha) se suelen sembrar alcaceres o vallicos (intercalares que también se encuentran asociados a la remolacha forrajera y los nabos con 190 ha) (González Cobas, 1960).

Diez años más tarde hay prueba de mejora en el rendimiento lechero pues la producción supera los cien mil litros diarios (frente al cálculo de 30.000 litros diarios que cabe deducir de los datos de González Cobas) según la información recuperada para 1970 por Efrén García Fernández en Luarca. Arquitectura y paisaje en unas normas urbanísticas (1988). Aunque el número de cabezas de vacuno habría descendido hasta 12.205. Puede tener que ver en ello una disminución del número de explotaciones relacionado con la dinámica demográfica regresiva experimentada en el concejo entre 1950 y 1970, pasando de más de 25.000 habitantes a menos de 20.000 , probablemente a causa de los traslados a los principales centros 


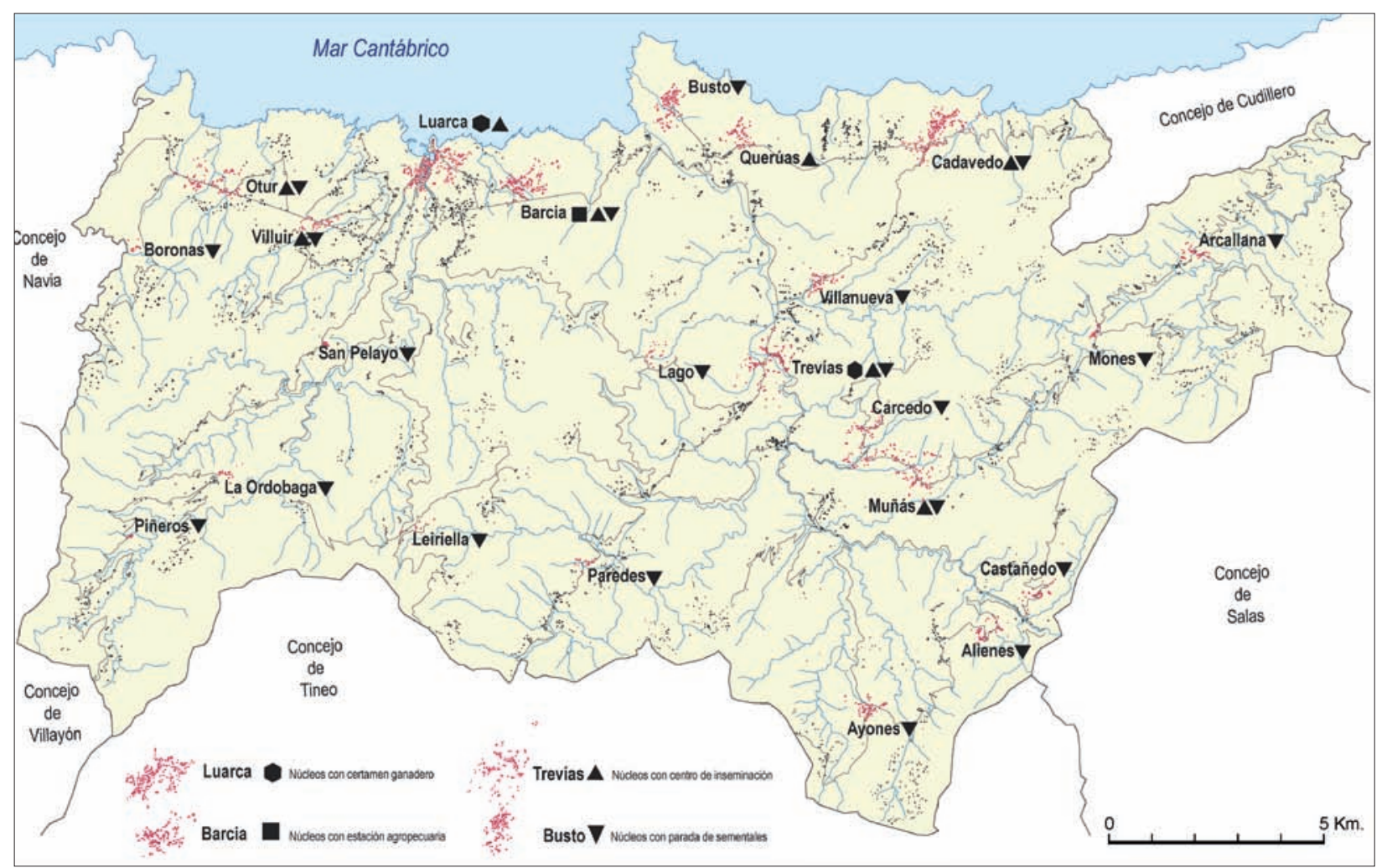

Fig. 5. Localización de los núcleos que participan en la transformación ganadera del concejo de Luarca a comienzos de la década de 1960, de acuerdo con la información proporcionada por Modesto González Cobas, acogiendo certamen ganadero, estación agropecuaria, centro de inseminación o parada de sementales. Mapa elaborado a partir de la base cartográfica a escala 1:40.000 del PGo de Valdés.

industriales y de servicios de la región (Casariego, 1973). En la misma fecha el Servicio del Catastro de la Riqueza Rústica ofrece la siguiente distribución de la superficie agrícola: entre las tierras labradas, $3.700,15$ ha corresponden a plantas herbáceas, 3.669,63 ha a labradío de cereal; y entre las tierras cubiertas con especies forestales o pastos, $5.247,82$ ha son de plantas herbáceas, $4.073,76$ ha de praderas y $1.174,06$ ha de pastos sin arbolado.

En cualquier caso, a comienzos de la década de 1970 el concejo parece haber mejorado su riqueza agropecuaria merced a los créditos concedidos y a los servicios prestados por los distintos organismos del Estado, aparte de la aplicación de avances científico-técnicos, estimulada por la demanda de la agroindustria. Aunque, en consideración del periodista Jesús Evaristo Casariego (1973), no se presta suficiente cuidado a todos los elementos que rigen la vida en el medio rural, incluido el mantenimiento de caminos, carreteras, viviendas y alumbrado. En Luarca y sus problemas, Casariego insiste en que el terreno debe dedicarse a la alimentación del ganado y no tanto a la explotación forestal de especies alóctonas pues en la fecha:
[...] la leche, la carne, el cuero, están en alza y son riqueza. Por de pronto, buena parte de la zona llana, llamada de «la marina», al este y al oeste de Luarca, debe ser transformada de pinar en prado, y dar albergue a granjas modernas capaces de sustentar a muchas familias y de poner en circulación efectiva mucha riqueza que a su vez aumentará el comercio y la industria en la villa. E igual ir haciendo en los grandes valles y en todo el Concejo que no sea bosque noble. Y dejar pinos y eucaliptos para terrenos de contención o que no den otra cosa. (Casariego, 1973)

El mismo autor aboga por la concentración parcelaria por resultar «más cómoda y más productiva la explotación del campo», cuya materia prima habría de aprovechar una «industria ligera» apoyada en las tradiciones artesanas y las materias primas del lugar. Asegura que buen ejemplo de ello existe en otras comarcas ganaderas y en la misma de Luarca con la industria láctea, encontrando asiento en esa época empresas de capital forastero «susceptibles de aumento si se acrecienta el censo ganadero».

Algunas de las expectativas de Casariego se van a cumplir en los años siguientes con la aplicación de operaciones de concentración parcelaria para solventar los 

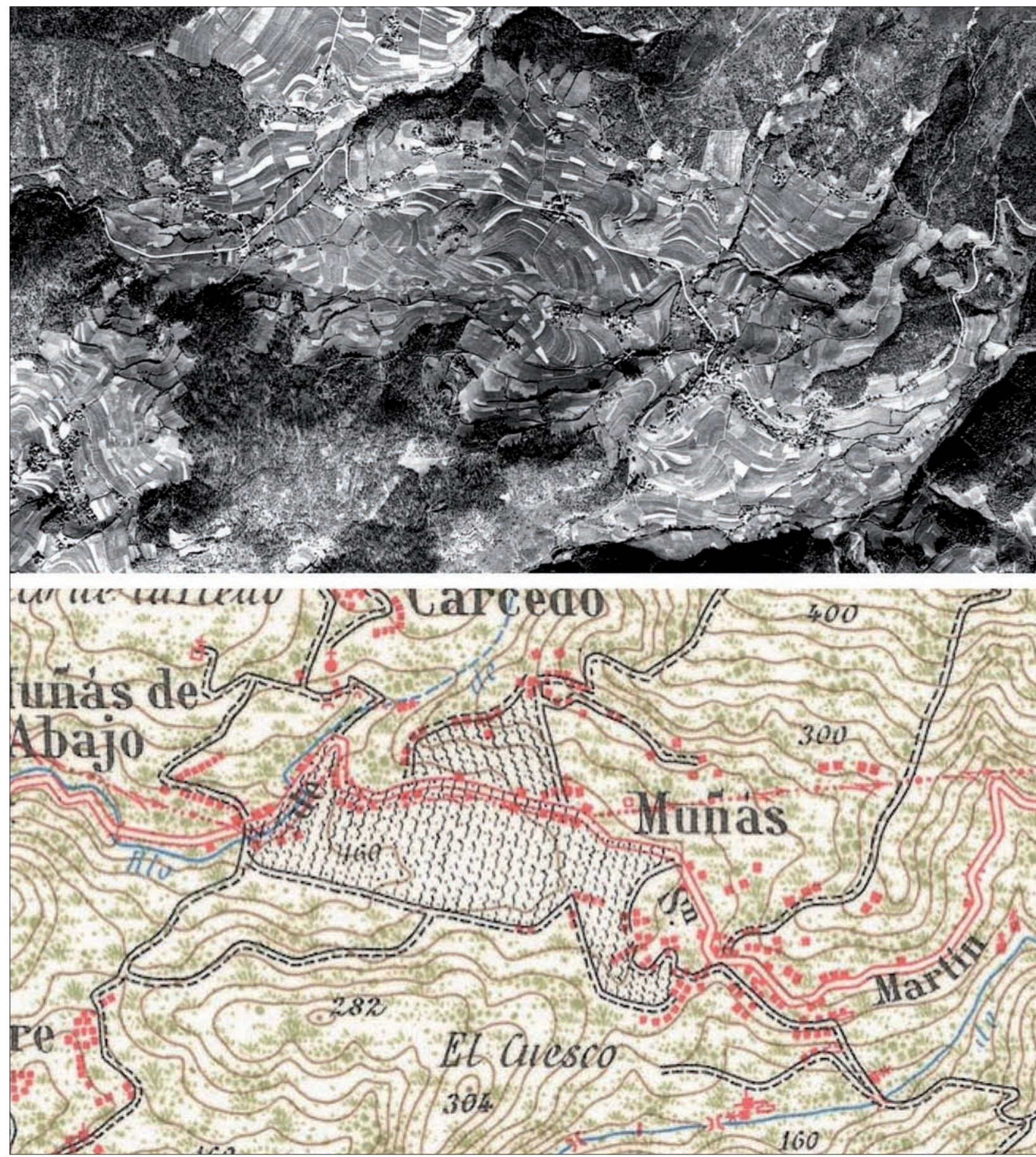

Fig. 6. La especialización productiva en las parroquias de Carcedo y Muñás se traduce en la progresiva generalización de la raza frisona, de mayor aptitud lechera, y la consiguiente reorientación del terrazgo para atender las necesidades específicas de este ganado: se tiende a sembrar maíz forrajero y se introducen el raigrás italiano e inglés, el trébol y la alfalfa. La sustitución de los aprovechamientos tradicionales y una concentración de usos en terrenos contiguos, o el aumento del tamaño de algunas parcelas (con el objetivo de favorecer la mecanización), aún al margen de la concentración parcelaria oficial, se perciben en las parroquias estudiadas al finalizar la década de 1960, al tiempo que arranca la actividad de la 


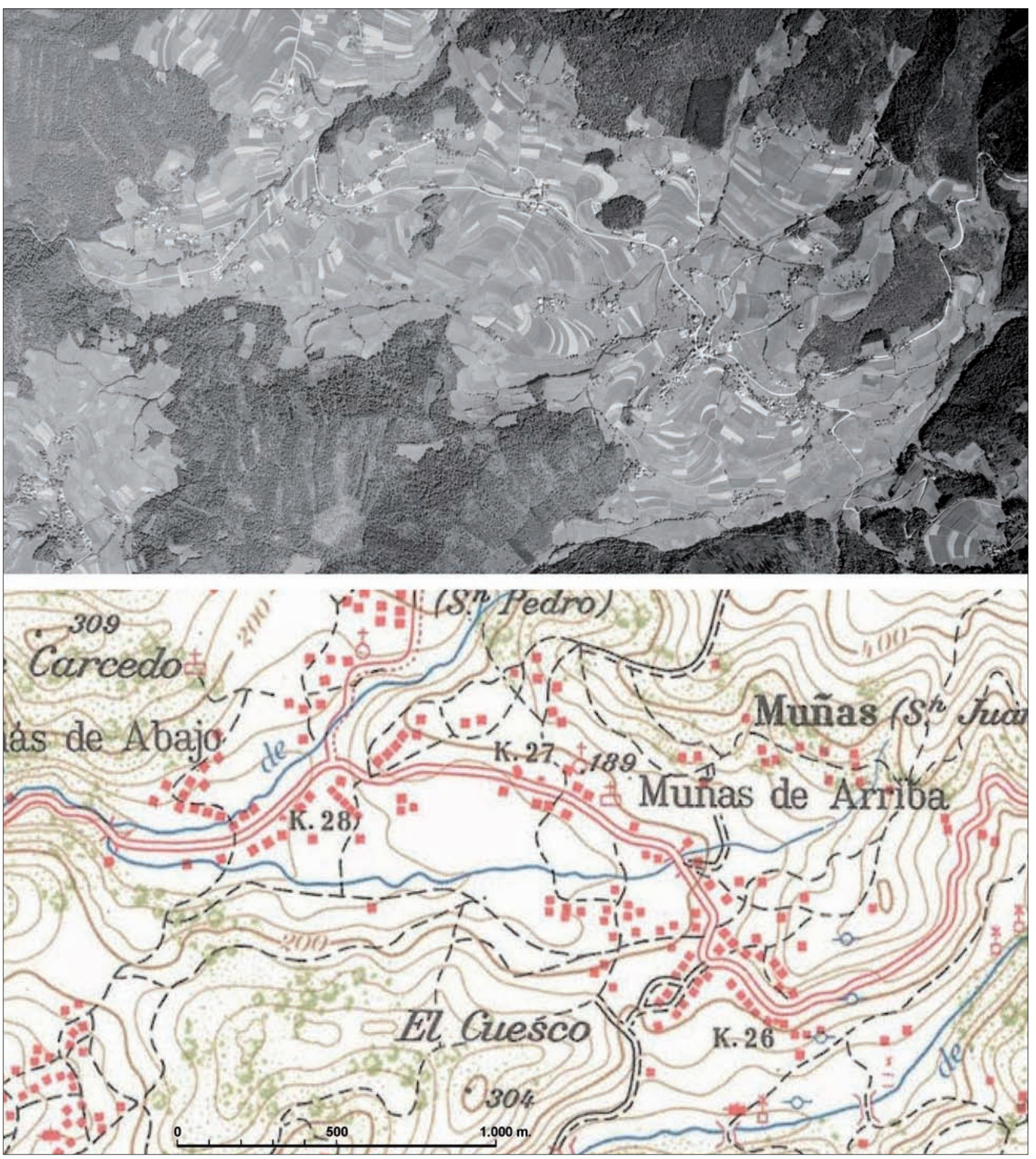

cooperativa. Los cambios se advierten comparando las imágenes aéreas de 1956 (imagen superior izquierda, fragmento del fotograma 29001 del Vuelo Americano, tomado en octubre de 1956) y 1970 (imagen superior derecha, fragmento del fotograma 3804 del Vuelo de la Diputación, tomado en el verano de 1970). Los símbolos correspondientes al espacio de labor y a los prados no aparecen, sin embargo, en la edición de 1975 del MTN a escala 1:50.000 (imagen inferior derecha, fragmento de la hoja 27 Tineo) frente a la representación del mismo sector en la edición de 1941 (imagen inferior izquierda). 
problemas de explotación vinculados a la fragmentación excesiva del terrazgo. Tienen lugar en la década de 1970 en Canero y Otur y a finales de la década siguiente en Carcedo, donde la actuación se declara de utilidad pública y urgente ejecución en 1988 (Consejería de Agricultura y Pesca, 1988). Se trata, con todo, de una actuación limitada en el espacio, de modo que la adaptación de la actividad agraria a la economía de mercado se produce sobre la base de una estructura parcelaria heredada. No obstante, la mecanización gana terreno, aumenta la presencia de especies orientadas a la producción lechera y surgen algunas iniciativas de asociación de ganaderos tanto para la comercialización como para la transformación láctea (Fernández Pereiro, 1992; Langreo Navarro, 1995, Fernández García y Quirós Linares, 2001).

Las experiencias de innovación agraria señaladas más arriba tienen lugar en zonas del concejo que, por sus características topográficas y geomorfológicas, resultan más aptas para la reorientación de las explotaciones: las situadas en la rasa costera y algunas áreas más abiertas y tendidas de los valles de los ríos Negro, Esva y sus afluentes. Aquí se localizan, además, algunos de los sectores más provechosos y fértiles, como el de la vega de Canero en el curso bajo del río Esva, de llamativo paisaje por el paso de uno de los históricos viaductos del ferrocarril Gijón-Ferrol (González Cobas, 1960; Fernández Pereiro, 1992; Fernández García y Quirós Linares, 2001). O el de las parroquias de Carcedo y Muñás, que suman $40 \mathrm{~km}^{2}$ en el sector oriental del municipio (Costales García, 2000) sobre los valles de los ríos Mallene, La Fervencia, Carcedo y Muñás (afluentes directos del Esva, por el este, los dos primeros y del Orio, también por el este, los dos últimos). El ejemplo de Carcedo y Muñás es especialmente significativo: su población inicia la especialización productiva avanzada la década de 1960 y encabeza, a partir de 1968, una experiencia pionera de cooperativismo moderno, basada en principios de funcionamiento solidario, colaborativo y democrático que arraigan posteriormente en todo el concejo y en el occidente asturiano ${ }^{7}$.

\footnotetext{
${ }^{7}$ La información relativa a la especialización productiva de las parroquias de Carcedo y Muñás procede de dos entrevistas mantenidas el 3 de agosto y el 6 de septiembre de 2016 con trabajadores vinculados a su movimiento cooperativo: Manuel Pérez Rodríguez, vecino de Carcedo, diputado regional entre 1983 y 1999 por el PSOE, miembro fundador de la Agropecuaria San Pedro y primer Secretario y miembro fundador de la Unión de Campesinos Asturianos; y José Manuel Peláez Pérez, vecino de Muñás de Abajo, quien ha desarrollado íntegramente su trayectoria profesional en el movimiento cooperativo asturiano desde su experiencia inicial en la Agropecuaria San Pedro de Carcedo y Muñás. Se agradece a ambos la colaboración y el alto interés con que han seguido la realiza-
}

Uno de los indicios más claros del cambio en las prácticas ganaderas en Carcedo y Muñás fue, como en el conjunto de Asturias, la progresiva generalización de la raza frisona. Si con anterioridad a 1960 proliferaban los cruces de vaca parda alpina con rubia, entre otros, la comprobación del rendimiento lechero de algunos ejemplares frisones supuso un aumento muy de su proporción hasta constituir, en pocos años, prácticamente el $80 \%$ de la cabaña de vacuno de estas parroquias. Se difundía así a finales de los años sesenta y principios de los setenta una tendencia más tempranamente generalizada en las provincias vascas y en Santander, y bien conocida en el oriente asturiano y en Siero (donde llegaban a comprar incluso ganaderos gallegos). La producción anual por res superó entonces los 2.400-2.500 litros como promedio de la vaca mestiza para alcanzar los 3.000 litros de la raza frisona (aumentaría hasta los 4.500 litros a mediados de los años ochenta en virtud de mejoras genéticas).

La introducción de ganado de mayor aptitud lechera suponía cambios importantes en el terrazgo: la siembra de maíz forrajero como base de la alimentación del ganado aumentaba y se introducía la pradera artificial (raigrás italiano e inglés, trébol y algo de alfalfa), manteniéndose no obstante algunos espacios dedicados a huerta en los anexos de las viviendas. En la parte baja de las casas y debajo de los hórreos y paneras se ubicaban inicialmente las cuadras. El mantenimiento de este ganado también exigía la disponibilidad de determinados consumos intermedios y servicios que, al principio, antes de que surgiera la cooperativa local, eran atendidos por agentes externos como la Cooperativa Avícola de Gijón, suministradora de piensos compuestos. En este sentido, en razón de sus importantes consecuencias en las formas de organización económica y social, sería muy relevante la creación de la cooperativa denominada Agropecuaria San Pedro de Carcedo y Muñás en 1968, considerada primera cooperativa democrática de Asturias, en la que se involucraron ganaderos de seis localidades situadas en las parroquias mencionadas: Carcedo, Muñás de Abajo, Muñás de Arriba, Ferrera, Villar y La Cadorna.

El germen de este movimiento cooperativo tuvo que ver con el deseo de superar algunas limitaciones que suponía el abastecimiento ejercido por los almacenes

ción de este trabajo. Por otro lado, la autora de referencia en el estudio del sector lácteo español y asturiano, Alicia Langreo Navarro, aporta información de interés en su obra Historia de la industria láctea española. Una aplicación a Asturias, al referirse a la historia de Nestlé, Pascual y Valdés SAT. 

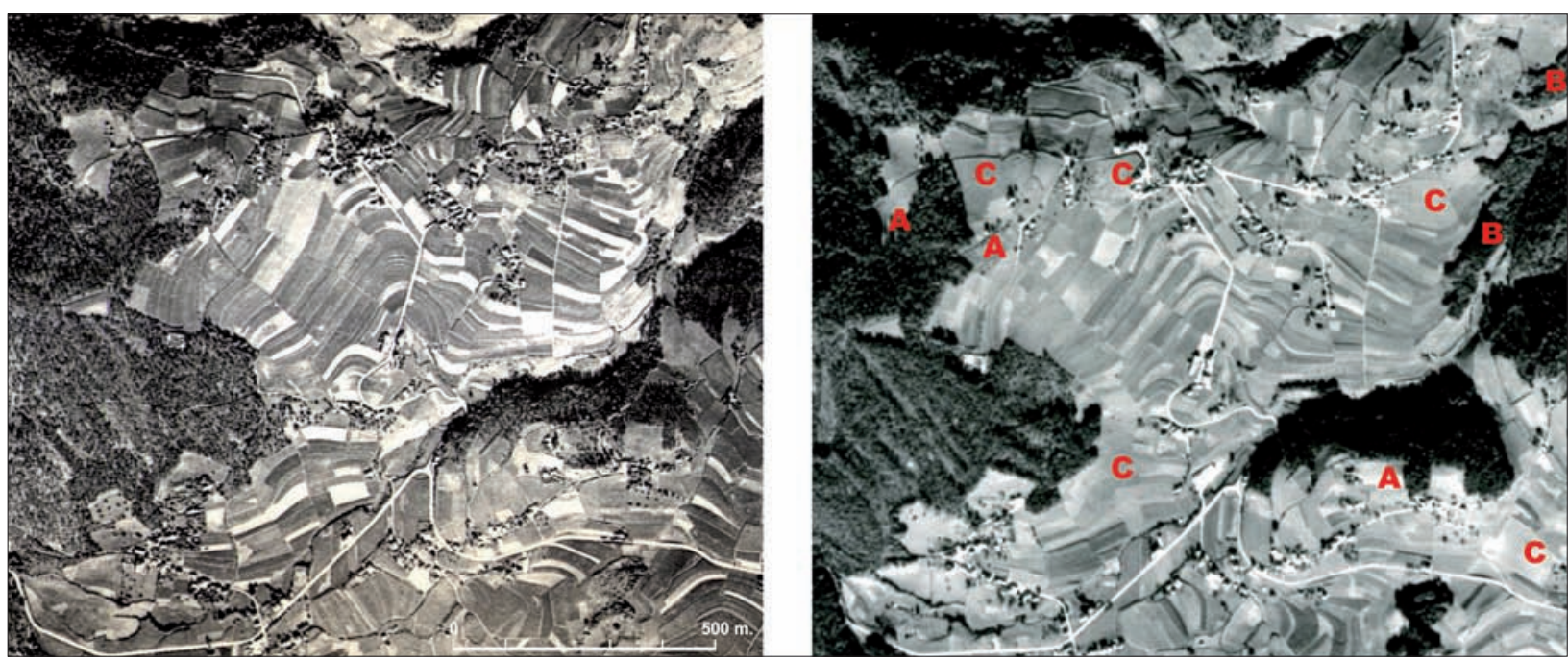

FIg. 7. En el entorno de los núcleos de Carcedo y Muñás de Abajo se llevaron a cabo operaciones de roturación de montes para dedicar a aprovechamiento ganadero (A), al tiempo que, por otro lado, el uso forestal avanzaba sobre algunos terrenos menos favorecidos topográficamente o, probablemente, afectados por el cese de la actividad agroganadera en explotaciones cuyos titulares se desplazan a las áreas urbanas de la región (B), fenómeno generalizado en el concejo durante el período estudiado. En cualquier caso, aun cuando la fragmentación del terrazgo es considerable en 1983 (a la derecha, fragmento del fotograma 4562-08 del Ministerio de Hacienda, tomado en octubre de 1983), se observan diversos ejemplos de concentración de uso en parcelas contiguas (C), inexistentes en 1956 (a la izquierda, fragmento del fotograma 29001 del Vuelo Americano, Serie B, tomado en octubre de 1956).

dependientes de las cámaras agrarias vinculadas al sindicato vertical. Se deseaba progresar en la adquisición en común de alimentación, determinados servicios (técnicos, veterinarios, etc. ${ }^{8}$ ) e insumos (fertilizantes, semillas pratenses, mezclas de piensos, medicamentos, etc.) con precios ventajosos. Se pretendía igualmente acceder a una más amplia información sobre las innovaciones agrarias y a programas formativos, culturales y de ocio. Si la parroquia constituía una unidad de organización vecinal adecuada para aglutinar a los campesinos ${ }^{9}$, la afinidad que otorgan la contigüidad y la red de comunicaciones en los valles de Mallene, La Fervencia, Mu-

${ }^{8}$ A través de la cooperativa se llega a disponer de programas sanitarios, reproductivos y de control de secado de las reses a mediados de los años ochenta como vía para la mejora del mantenimiento del ganado y, en definitiva, de la productividad.

${ }^{9}$ La iniciativa de Carcedo y Muñás inspiró a otras cooperativas parroquiales en el área de Luarca, de las que llegó a haber diez, y el modelo se extendió por el occidente de la región. Las de Luarca establecieron vínculos estables y crearon un consejo cuyos componentes, elegidos por votación cada seis meses, tenían el cometido de adquirir alimentación animal y fertilizantes de alta calidad. Estas cooperativas también dieron lugar al denominado Centro Contable, con sede en Trevías, que surge en 1986 apoyado por el gobierno regional. El Centro Contable se encargó principalmente de asuntos fiscales, de asesoría laboral y contabilidad. Este órgano constituiría posteriormente el germen del Centro Intercooperativo del Campo de Asturias, puesto en marcha en 1989 e integrado desde 2005 en la Sociedad Cooperativa Delagro junto a otras cooperativas de segundo grado de Galicia (Cecoop) y Cantabria (Sergacan). ñás y Carcedo explica que se tratara de un movimiento construido en torno a las entidades de las dos parroquias señaladas.

Al margen de los cambios en la organización del terrazgo, la reorientación de las explotaciones también conllevó una roturación de montes para dedicar a pastizal entre los años 1970 y 1980, aunque con una extensión limitada; tuvo lugar en las zonas de La Cuesta (en el área septentrional del núcleo de Muñás de Abajo), El Atayu y El Bravo María Florenta (al oeste de Carcedo). Además, en el área de Laplame (sector sur de la vega del río Carcedo, junto a Muñás de Abajo) se preparó en los años 1973 y 1974 un campo experimental de colza e igualmente se hizo un ensayo de haba de soja. Pero hasta 1988 no se produjo la concesión de concentración parcelaria, en este caso para Carcedo, previa recogida de firmas para su impulso y con gestiones que se dilataron varios años ${ }^{10}$. Por otro lado, en la primera mitad de la década de 1970 fue significativa la introducción de vehículos motorizados para el trabajo del terreno y el transporte del forraje, sustituyendo a los animales. Los primeros eran de marca Pacuali y 14 CV. Llegaron a Carcedo y Muñás por inicia-

\footnotetext{
${ }^{10}$ En Carcedo se acometió, al mismo tiempo y por primera vez en la región, la concentración de montes, motivo por el que se retrasó la operación unos años.
} 


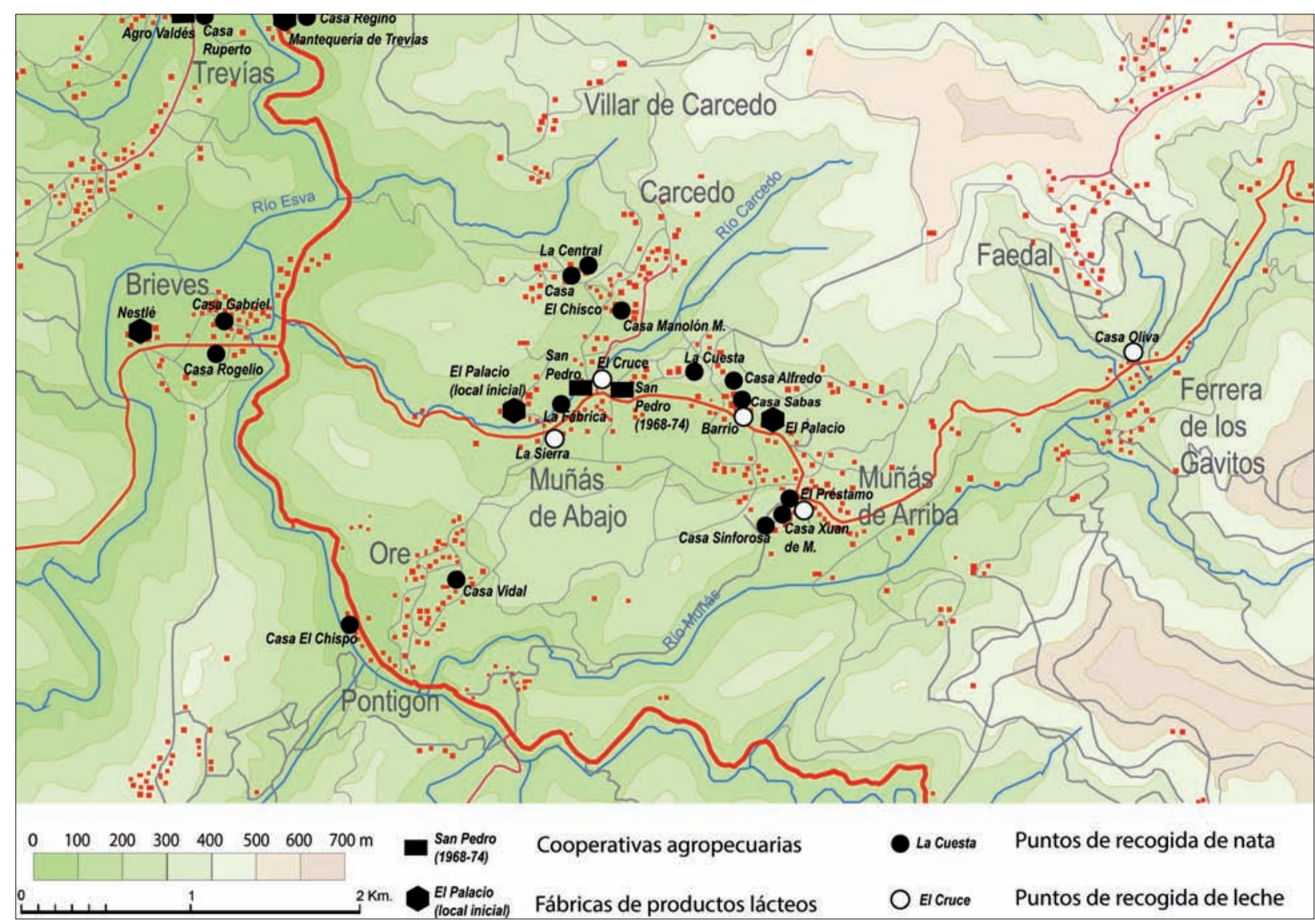

FIG. 8. Localización de las cooperativas agropecuarias, de las fábricas de productos lácteos y de los lugares en que se recogían las natas en las parroquias de Muñás, Carcedo, Brieves y Trevías en el período 1960-1975. Se incluye la localización de los puntos de recogida de leche líquida en los valles de Muñás y Carcedo. La información ha sido proporcionada por Manuel Rodríguez Pérez y José Manuel Peláez Pérez. El mapa se elabora sobre la base de la Hoja 27 Tineo del MTN a escala 1:50.000 en su edición de 1975 .

tiva de ganaderos que pretendían adoptar innovaciones ya conocidas en otras áreas de la región.

El movimiento cooperativo encontró además un apoyo importante en el desarrollo del servicio de Extensión Agraria, en aquel tiempo dependiente del Ministerio de Agricultura, con una orientación técnica y de asistencia al ganadero que facilitó, entre otros aspectos, la introducción de silos en el ámbito geográfico analizado e impulsó la transformación de las cuadras ${ }^{11}$. También impulsó cursos en horario nocturno para los ganaderos, impartidos en buena medida por ingenieros agrónomos y

\footnotetext{
${ }^{11}$ Las cuadras se modificaron en los mismos locales preexistentes introduciendo nuevos amarres y separaciones que permitían acoger un mayor número de reses. Posteriormente, a partir de 1977, comenzaron a habilitarse locales específicos separados de las viviendas y más preparados para la introducción de tecnología y el almacenaje de piensos, forrajes, etc.
}

veterinarios, que abordaban temas referidos a la alimentación del ganado, al ensilaje, al ordeño, a los cuidados sanitarios y las enfermedades, etc.

Del movimiento cooperativo de Carcedo y Muñás merece una mención especial el denominado grupo de comercialización, que entró en funcionamiento con posterioridad a la creación de la Agropecuaria para velar por los intereses ganaderos en su relación con el subsector industrial. Mantequerías Arias, de Oviedo, y El Palacio, con sede inicialmente en Muñás de Abajo y luego en Muñás de Arriba, venían siendo las principales empresas recogedoras de materia prima para su procesamiento en fábricas, apoyándose en las desnatadoras distribuidas en la zona. Pero en la segunda mitad de la década de 1960 se recoge ya leche líquida en lugar de natas, siendo Arias, Nestlé y posteriormente Central Lechera Asturiana, las primeras en hacerlo. En este contexto, Nestlé, instalada 


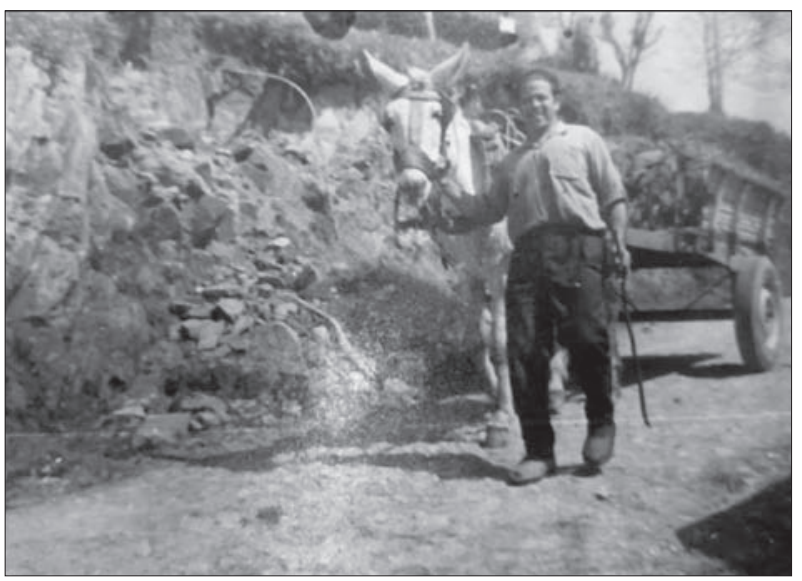

FIG. 9. Labores agrarias en Carcedo. En la imagen aparece Avelino Martínez, recogedor de leche en bidones para Nestlé en la parroquia señalada. También trabajó en tareas de recogida para El Palacio. Fuente: familia de Avelino Martínez.

en Brieves desde 1966, cerca de Carcedo y Muñás y con muchos trabajadores en el entorno, estimula la creación del grupo de comercialización para frenar la previsible captación de socios por parte Central Lechera Asturiana. La empresa suiza decide además establecer precios muy ventajosos e incluso sobreprecios por litro de leche con el fin de mantener su área de influencia. Con todo, Central Lechera Asturiana llega a tener un vínculo importante en el área estudiada, mayor que el de otra empresa asturiana entonces emergente, la de Industrias Lácteas AsturianasReny Picot (en otras ocasiones y áreas geográficas del occidente ocurriría de manera diferente).

Al llegar los años ochenta otras entidades cobran protagonismo, sobre todo Pascual, con sede en Aranda de Duero, que inicia su recogida en Asturias después de haber pactado una subida del precio de la leche con la cooperativa de Carcedo y Muñás. Pascual introduce entonces en estas parroquias los tanques de frío, importados desde Francia, generando un nuevo tipo de recogida que también impulsa Clas para espaciar el paso por cada explotación: se recogerá en cuba cada segundo día, en lugar de las dos tomas diarias practicadas por Arias o Nestlé en los años en que se iniciaba la recogida de leche líquida (en invierno era solo de mañana). Otra experiencia que evidencia la orientación láctea de la producción ganadera local será la creación de Valdés SAT en Canero a partir de 1986 (adquiriendo la fábrica que pertenecía a Arias), con participación de algunos ganaderos del grupo de comercialización mencionado más arriba (Langreo Navarro, 1995). Para entonces, sin embargo, se dejan ya notar algunos efectos de la adaptación del sector agrario a la entrada en la Comunidad Económica Europea, unidos a los propios de una práctica ganadera exigente en el contexto de plena integración en la economía de mercado. El cese de la actividad ganadera es importante en la región y en los pueblos del entorno de la cooperativa supone que aproximadamente 30 familias detengan su explotación entre la década de 1960 y la de 1980 (pasando de 100 casas con producción ganadera a únicamente 70).

\section{CONCLUSIONES}

La integración de los mercados, junto al incremento y la concentración geográfica de la demanda de productos lácteos, resultantes de la industrialización, de la progresiva urbanización y de la difusión de nuevas pautas alimentarias, incentivaron el suministro de materia prima a la industria láctea como vía de inserción de la población agraria asturiana en la economía de mercado. En ese contexto, la adaptación de las explotaciones ganaderas en términos de orientación productiva, procedimientos, rendimiento y gestión vinieron a representar un reto para el campesinado, que hubo de superar obstáculos como la fragmentación parcelaria, las características físicas de los terrenos, poco aptos para la mecanización, y la rezagada incorporación de innovaciones técnicas, higiénicosanitarias y económicas.

Acomodarse al nuevo sistema socioeconómico y territorial asturiano supuso, para quienes optaron por la especialización láctea, transformar el terrazgo, intensificar las prácticas ganaderas e invertir sumas importantes en la adquisición de inputs. Exigió al ganadero un rendimiento y una capacidad de inversión a los que difícilmente podía hacer frente con desahogo. Se entiende así la necesidad del apoyo y asesoramiento ofrecido por los organismos oficiales y, por otro lado, la situación de dependencia respecto de sus principales clientes, las empresas lácteas, protagonistas al tiempo de una concentración empresarial a veces contraria a los intereses del productor agrario. En el momento en que se expandía la especialización productiva entre los ganaderos, se producía el crecimiento de los negocios de un pequeño grupo de empresas industriales exitosas en los mercados y capaces de influir, por su capital y su estructura organizativa, en la articulación de las redes de recogida, en el precio de la leche o en la difusión de innovaciones en las explotaciones.

Surgieron entonces iniciativas de cooperativismo agrario dirigidas a mejorar la posición de los ganaderos en sus relaciones con los restantes agentes implicados en la elaboración de productos lácteos. La creada en Carcedo 
y Muñás en 1968 fue ejemplo de una forma de organización vecinal que atendió a intereses económicos compartidos e integró beneficios sociales y culturales para la población local. La fortaleza de este movimiento cooperativo valdesano, apoyado en un funcionamiento colaborativo y democrático, mereció negociaciones favorables con algunas de las empresas no asturianas de la industria láctea de la época (Nestlé, Pascual...), aparte de las muy importantes compañías con origen en nuestra región, que tuvieron en particular consideración a los ganaderos de estas parroquias rurales a la hora de consolidar su presencia en el litoral occidental. Ello no impidió, sin embargo, que disminuyera progresivamente el número de familias dedicadas a la ganadería de leche y la actividad tendiera a concentrarse en unas pocas explotaciones, en un proceso marcado por la compleja viabilidad debida a las exigencias de rendimiento, tamaño y mecanización. Y aún lo seguiría haciendo tras el ingreso en la Comunidad Económica Europea, con el sistema de cuotas lácteas y la competencia continental. No obstante, el movimiento cooperativo arraigaba en el occidente de la región, inspirado por la experiencia de Carcedo y Muñás, y sentaba las bases para la constitución de entidades intercooperativas a escala comarcal, regional e interregional.

\section{BIBLIOGRAFÍA}

Caja de Ahorros de Asturias (1969): La economía asturiana en 1968 y análisis del sector agrario en Asturias. Caja de Ahorros de Asturias, Oviedo, 199 pp.

Campo Astur. Órgano de la Cámara Oficial Sindical Agraria y de sus Hermandades de Labradores y Ganaderos, núms. 326 (diciembre de 1967), 329 (marzo de 1968), 355 (mayo de 1970), 359 (septiembre de 1970).

CASARIEGO, J. E. (1973): Luarca y sus problemas. Imp. La Cruz, Oviedo, 23 pp.

Catálogo oficial de la Exposición de Productos Regionales del Noroeste de España. Gijón, del 1 al 31 de agosto de 1946 (sin paginación).

Collantes Gutiérrez, F. (2014): «La evolución del consumo de productos lácteos en España, 1952-2007». Revista de Historia Industrial, núm. 55, pp. 103-134.

Consejería de Agricultura y Pesca (1988): «Decreto 71/88, de 9 de junio, por el que se declara de utilidad púbica y urgente ejecución la concentración parcelaria de la zona de Carcedo (Luarca)». Boletín Oficial del Principado de Asturias, núm. 146, 24 de junio de 1988, pp. 2.981-2.982.
Diputación Provincial de Asturias (1946): «Informe del Servicio de Agricultura y Ganadería», en Catálogo Oficial de la Exposición de productos regionales del Noroeste de España. Gijón, del 1 al 31 de Agosto de 1946 (sin paginación).

EsPejo Marín, C. (2001): «Modernidad y tradición en la fabricación de queso en España». Papeles de Geografía, núm. 33, pp. 81-109.

Espejo Marín, C. (1997): «Sistemas de explotación del ganado en la región de Murcia». Papeles de Geografía, núm. 26, pp. 79-92.

Fernández Cuesta, G., y J. R. Fernández Prieto (1999): Atlas Industrial de España. Nobel, Oviedo, 205 pp.

Fernández García, F. (1990): «La evolución reciente de la actividad agroganadera en Asturias», en L. V. García Merino, R. González Pellejero, J. M. Sierra Ramírez y R. Fuente Prieto (comps.): Los espacios rurales cantábricos y su evolución. Universidad de Cantabria/Asamblea Regional de Cantabria, Santander, pp. 94-105.

- A. Maceda Rubio y F. Rodríguez GutiérRez (1990): «El espacio rural en Asturias», en F. J. Fernández Conde (dir.): Historia de Asturias. T. III, Editorial Prensa Asturiana, Oviedo, pp. 653-668.

- y F. Quirós Linares (2001): Atlas aéreo de Asturias. Los paisajes del siglo XX. Editorial Prensa Asturiana, Oviedo, 829 pp.

- y F. RodríGuez GutiÉRREz (1993): «Transformaciones recientes en el espacio rural asturiano: evolución de los cultivos y de la cabaña ganadera (1940-1990)», en A. Gil Olcina y A. Morales Gil (eds. lits.): $\mathbf{M e}$ dio siglo de cambios agrarios en España. Instituto de Cultura Juan Gil-Albert/Diputación Provincial de Alicante, Alicante, pp. 859-884.

- y F. RodríGuez GutiérRez (1992): «La evolución reciente del espacio rural», en G. Morales Matos (dir.): Geografía de Asturias. T. I, Editorial Prensa Asturiana, Oviedo, pp. 177-192.

Fernández García, P. (2000a): Catálogo de herramientas y útiles tradicionales para elaborar el queso. Muséu Etnográficu de la Llechería, La Foz de Morcín, 51 pp.

- (2000b): La manteca de vaca en la sociedad tradicional asturiana. Muséu Etnográficu de la Llechería, La Foz de Morcín, 56 pp.

Fernández Pereiro, J. (1992): «El concejo de Valdés» en G. Morales Matos (dir.): Geografía de Asturias. T. III, Editorial Prensa Asturiana, Oviedo, pp. 2-20.

Feo Parrondo, F. (1997): «Agroindustria y comercialización de productos agropecuarios». Geographicalia, núm. 34, pp. 111-135. 
FERrer Regales, M. (1963): La ganadería bovina en la región asturcántabra. Instituto de Estudios Asturianos, Oviedo, $114 \mathrm{pp}$.

García Fernández, E. (1988): Luarca. Arquitectura y paisaje en unas normas urbanísticas. Colegio Oficial de Arquitectos de Asturias, Oviedo, 323 pp.

García Fernández, J. (1975): Organización del espacio y economía rural en la España atlántica. Siglo XXI, Madrid, 332 pp.

García Pascual, F. (1993): «Ganadería, agroindustria y territorio. El fenómeno de la integración en la ganadería leridana». Agricultura y Sociedad, núm. 66, pp. 125-158.

GonzÁlez CoBAs, M. (1960): Guía turística, histórico descriptiva de Luarca y su antiguo concejo de Valdés. Publicaciones de la Junta Municipal de Turismo, Luarca, 123 pp.

INCLÁN SuÁREZ, F. (1999): «Las enseñanzas agropecuarias en Asturias», en Actas del II Congreso de Bibliografía Asturiana. Consejería de Educación y Cultura, Oviedo, pp. 385-398.

JuAn i FenOllar, R. (1978): «La teoría de la agroindustrialización y la estabilidad del campesinado». Agricultura y Sociedad, núm. 9, pp. 165-186.

Langreo Navarro, A. (1978): «Análisis de la integración vertical en España». Agricultura y Sociedad, núm. 9, pp. 187-205.

- (1995): Historia de la industria láctea española: una aplicación a Asturias, 1830-1995. Ministerio de Agricultura, Pesca y Alimentación/Secretaría General Técnica, Madrid, $551 \mathrm{pp}$.

- R. Soria Gutiérrez y M. Rodríguez-ZúÑIGa (1988): «La agricultura contractual: el sector lácteo asturiano». Revista de Estudios Agrosociales, núm. 144, pp. 221-254.

LoRENZI FernÁndeZ, E. (2004): «La producción láctea y la transformación del campo asturiano», en J. Rodríguez Muñoz (coord.): Los asturianos, raíces culturales y sociales de una identidad. Editorial Prensa Asturiana, Oviedo, pp. 215-232.

Maceda Rubio, A. (1992): «El espacio rural asturiano: las transformaciones del siglo XIX», en G. Morales Matos (dir.): Geografía de Asturias. T. I, Editorial Prensa Asturiana, Oviedo, pp. 161-176.

- (1984): «La industria agroalimentaria en Asturias». Ería, núm. 4, pp. 47-69.

Ministerio de EduCaCión Nacional (1960): «Orden de 26 de julio de 1960 por la que se aprueba el Plan de estudios, cuadro-horario y cuestionarios del Bachillerato Laboral Superior de la Modalidad Agrícola Ga- nadera, correspondiente a la especialidad de "Industrias Lácteas"». Boletín Oficial del Estado, núm. 197, de 17 de agosto de 1960, pp. 11613-11622.

Ministerio de Industria y Comercio (1944): «Comisaría General de Abastecimientos y Transportes. Circular número 448 sobre libertad de fabricación y contratación del queso y de la manteca elaborados con leche de vaca». Boletín Oficial del Estado, núm. 93, 2 de abril de 1944, p. 2.671.

- (1945): «Comisaría General de Abastecimientos y Transportes (Dirección Técnica). Circular número 528 por la que se anula parcialmente las números 448 y 458 , en las que se dictaban normas sobre el comercio del queso y mantequilla». Boletín Oficial del Estado, núm. 185, 4 de julio de 1945, p. 86.

- (1946a): «Comisaría General de Abastecimientos y Transportes (Sección: Precios y Mercados). Circular número 584 sobre intervención de la manteca elaborada con leche de vaca oveja y cabra y prohibición de fabricar quesos elaborados con leche de vaca o con mezcla de leche de vaca y de oveja». Boletín Oficial del Estado, núm. 215, 3 de agosto de 1946, pp. 6.099-6.100.

- (1946b): «Comisaría General de Abastecimientos y Transportes (Dirección Técnica.- Sección Precios y Mercados). Circular número 609 por la que se autoriza la fabricación de quesos y se fijan los precios, así como a la mantequilla y nata». Boletín Oficial del Estado, núm. 356, 25 de diciembre de 1946, p.9.012. Ministerio de la Gobernación y Ministerio de AgriculTURA (1952): «Orden conjunta de ambos Departamentos de 31 de julio de 1952 por la que se aprueba el Reglamento por el que han de regularse las condiciones de la leche destinada al abasto público y de las Centrales Lecheras». Boletín Oficial del Estado, núm. 225, 12 de agosto de 1952, pp. 3.762-3.767.

NAdAl Oller, J. (1977): «Notas sobre la industria asturiana, de 1850 a 1935», en G. Ojeda Gutiérrez (coord.): Historia de Asturias. T. 9 (Edad Contemporánea II), Ayalga, Salinas, 1977, pp. 111-177.

OcAmpo SuÁrez-VAldés, J. (1990): Campesinos y artesanos en la Asturias preindustrial (1750-1850). Biblioteca Histórica Asturiana, Silverio Cañada Editor, Gijón, 366 pp.

OchoA Uriel, J. (1946): «Idea de la importancia económica e industrial de la ganadería en Asturias», en $\mathrm{Ca}$ tálogo oficial de la Exposición de Productos Regionales del Noroeste de España. Gijón, del 1 al 31 de agosto de 1946 (sin paginación).

PAÑEdA FernándeZ, C. (1981): «La economía rural en Asturias», en J. Cueto Alas (dir. gen.): Enciclopedia 
temática de Asturias. T. 7 (Ciencias sociales), Silverio Cañada Editor, Gijón, pp. 79-110.

Presidencia del Gobierno (1952): «Decreto de 18 de abril de 1952 sobre creación de centrales lecheras en municipios de más de 25.000 habitantes». Boletín Oficial del Estado, núm. 148, 27 de mayo de 1952, pp. 2.362-2.365.

- (1967a): «Orden de 31 de enero de 1967 por la que se convoca concurso para la concesión de una Central Lechera en Gijón (Oviedo)». Boletín Oficial del Estado, núm. 28 , 2 de febrero de 1967, p. 1.440.

- (1967b): «Orden de 21 de junio de 1967 por la que se convoca concurso para la concesión de una Central Lechera común a las localidades de Oviedo (capital), Langreo, Avilés y Mieres, constituyendo un área de suministro». Boletín Oficial del Estado, núm. 152, 27 de junio de 1967, p. 8.987.

- (1968): «Orden por la que se resuelve el concurso convocado para la adjudicación de una Central Lechera común al área de suministro integrada por Oviedo (capital), Avilés, Mieres y Langreo». Boletín Oficial del Estado, núm. 149, 21 de junio de 1968, p. 9.081.

Quirós LinARES, F. (1985): «Asturias en el Madoz», prólogo en P. Madoz (dir.): Diccionario GeográficoEstadístico-Histórico de España y sus posesiones de Ultramar. Ámbito Ediciones, Valladolid, pp. 1-11.

RodríGuez GutiérREz, F. (1996): «La evolución del sector ganadero en Asturias (1750-1995)», en R. Domínguez Martín (coord.): La vocación ganadera del norte de España. Ministerio de Agricultura, Alimentación y Medio Ambiente, Madrid, pp. 59-87.

San Miguel Cela, J. L. (1977): «La agricultura», en G. Ojeda Gutiérrez (coord.): Historia de Asturias. T. 9 (Edad Contemporánea II), Ayalga Ediciones, Salinas, pp. 51-109.
Segrelles Serrano, J. A. (1991): «La producción ganadera intensiva y el deterioro del medio ambiente», en Sociedad y territorio. XII Congreso Nacional de Geografía. Universitat de Valencia, Valencia, pp. 77-83.

- (1999): «Capitalismo y organización de los espacios ganaderos en España. El caso de la cooperativa agraria de Guissona». Investigaciones Geográficas, núm. 39, pp. 94-108.

- (2000): «Aproximación teórica y metodológica al estudio geográfico de la ganadería en España». Investigaciones Geográficas, núm. 41, pp. 107-121.

Sevilla Álvarez, J. (2009): La industria láctea en Asturias. Red de Museos Etnográficos de Asturias/Consejería de Cultura y Turismo del Principado de Asturias, Gijón, 302 pp.

SuÁrez Álvarez, J. L. (2003): Innovación industrial en Asturias. 100 hechos destacables. Ediciones Madú, Granda, 455 pp.

Velarde Fuertes, J. (1977): «Prólogo», en G. Ojeda Gutiérrez (coord.): Historia de Asturias. T. 9 (Edad Contemporánea II), Ayalga Ediciones, Salinas, pp.

Zorita Tomillo, E. (2001): «La investigación zootécnica española. Las razones de un fracaso». Archivos de Zootecnia, vol. 50, núm. 192, pp. 441-463.

\section{FUENTES DOCUMENTALES Y ESTADÍSTICAS}

CÁmARA de Comercio, Industria y NAVEGACión DE Oviedo: Censo de la Licencia Fiscal, años 1934 a 1970.

Consejería de Agroganadería y Recursos Autóctonos: Asturias, rendimientos lecheros en 1985. Datos comunicados al Ministerio en impreso G-L2.

Dirección General de Estadística: Anuario Estadístico de España, años 1943 y 1952. 